\title{
. \\ A cell surface-exposed protein complex with an essential virulence function in Ustilago maydis
}

\author{
Nicole Ludwig1, Stefanie Reissmann1, Kerstin Schipper1,5, Carla Gonzalez1, Daniela Assmann1, \\ Timo Glatter ${ }^{2}$, Marino Moretti', Lay-Sun Ma ${ }^{1,6}$, Karl-Heinz Rexer ${ }^{3}$, Karen Snetselaar ${ }^{4}$ and \\ Regine Kahmann (1) 1 凶
}

\begin{abstract}
Plant pathogenic fungi colonizing living plant tissue secrete a cocktail of effector proteins to suppress plant immunity and reprogramme host cells. Although many of these effectors function inside host cells, delivery systems used by pathogenic bacteria to translocate effectors into host cells have not been detected in fungi. Here, we show that five unrelated effectors and two membrane proteins from Ustilago maydis, a biotrophic fungus causing smut disease in corn, form a stable protein complex. All seven genes appear co-regulated and are only expressed during colonization. Single mutants arrest in the epidermal layer, fail to suppress host defence responses and fail to induce non-host resistance, two reactions that likely depend on translocated effectors. The complex is anchored in the fungal membrane, protrudes into host cells and likely contacts channel-forming plant plasma membrane proteins. Constitutive expression of all seven complex members resulted in a surface-exposed form in cultured $U$. maydis cells. As orthologues of the complex-forming proteins are conserved in smut fungi, the complex may become an interesting fungicide target.
\end{abstract}

T he smut fungus $U$. maydis is an important pathogen of corn ${ }^{1}$. Primary disease symptoms are plant tumours in which fungal hyphae differentiate into spores. U. maydis is a biotrophic pathogen requiring living plant tissue for proliferation. In its dikaryotic form, U. maydis develops appressoria that penetrate the plant cuticle and cell wall. Invading hyphae become encased by the plant plasma membrane, resulting in an extended interaction zone ${ }^{2}$. At this stage, plant responses elicited by fungal MAMPs (microbe-associated molecular patterns) are actively suppressed by a cocktail of mostly novel secreted effectors. A large number of these effectors are expressed during establishment of the biotrophic stage $^{3}$, and in this group are all six U. maydis virulence-promoting effectors functionally studied to date $e^{4-11}$. These effectors all interact with specific plant proteins and modulate their function either in the interface between fungus and surrounding plant plasma membrane or after translocation into invaded host cells ${ }^{12-14}$. The molecular mechanisms by which translocation is achieved are largely unknown ${ }^{15,16}$.

To investigate the establishment of biotrophy in more detail, we initiated a systematic deletion analysis of predicted novel effector genes from the biotrophy-associated group and selected those that are already highly induced during plant penetration ${ }^{17}$. Among the top five genes (Fig. 1a,b and Extended Data Fig. 1a), we identified two putative effector genes, stp2 (UMAG_10067) and stp3 (UMAG_00715), where single gene deletions in the solopathogenic strain SG200 (ref. ${ }^{18}$ ) abolished virulence completely (Fig. 1a,b). In addition, in this group was stp1 (UMAG_02475), a gene previously shown to abolish virulence when deleted alone ${ }^{18,19}$. In all cases, the loss of virulence could be complemented by introducing a single copy of the respective gene with or without a haemagglutinin (HA) affinity tag (Extended Data Fig. 1b). To study the course of plant colonization by the stp mutants, the mutations were introduced into SG200 strains expressing a cytosolic green fluorescent protein (GFP) marker that is induced in appressoria and stays active during colonization ${ }^{17,20}$. One day after infection with SG200, the appressorial marker was expressed and branching hyphae could already be detected in mesophyll tissue (Fig. 1c). At the same time point, stp1, stp2 and $s t p 3$ mutants had penetrated via appressoria, but branching did not occur and hyphae arrested in the epidermal layer (hence the name 'stop after penetration' or stp; Fig. 1c,d and Extended Data Fig. 1c). Staining with FM4-64 revealed integrity of the plant plasma membrane surrounding biotrophic SG200 hyphae (Fig. 1e). Upon mutant infection, the plant plasma membrane initially invaginated and was intact; however, at time points later than 2 days post infection (d.p.i.), the FM4-64 stain in infected cells accumulated in vesicular structures and the plasma membrane appeared disrupted (Fig. 1e). These are typical signs of programmed plant cell death $^{21-23}$. To obtain clues about the processes affected by the Stp proteins, we performed co-immunoprecipitations (co-IP) followed by mass spectrometry (MS) from extracts of maize leaves 3 d.p.i. with U. maydis strains expressing genes for either Stp1-HA, Stp2-HA or Stp3-HA under control of their native promoters. All HA-tagged proteins were detected after IP and subsequent western blot analysis (Extended Data Fig. 1d). However, instead of the expected plant interaction partners, we extracted a fungal protein complex consisting of Stp1, Stp3, Pep1, the putative effector UMAG_12197 (termed Stp4) and UMAG_01695 (termed Stp6) (Fig. 1f and Supplementary Data 1). stp6 has previously been identified as a Biz1-regulated gene with a critical virulence function (J. Kämper and M. Vraneš, personal communication), and Pep1 has been shown to inhibit

'Department of Organismic Interactions, Max Planck Institute for Terrestrial Microbiology, Marburg, Germany. ${ }^{2}$ Mass Spectrometry and Proteomics, Max Planck Institute for Terrestrial Microbiology, Marburg, Germany. ${ }^{3}$ Department of Evolutionary Ecology of Plants, Philipps-Universität Marburg, Marburg, Germany. ${ }^{4}$ Department of Biology, Saint Joseph's University, Philadelphia, PA, USA. ${ }^{5}$ Present address: Institut für Mikrobiologie, Heinrich-Heine-Universität Düsseldorf, Düsseldorf, Germany. ${ }^{6}$ Present address: Institute of Plant and Microbial Biology, Academia Sinica, Taipei, Taiwan.

凶e-mail:kahmann@mpi-marburg.mpg.de 

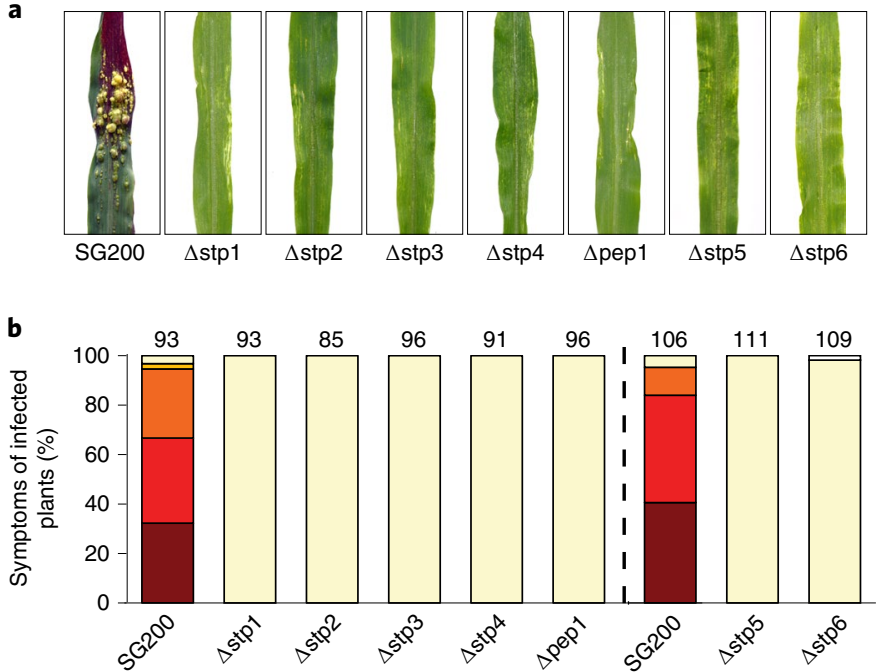

$\square$ No symptoms Chlorosis

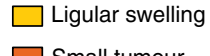
Small tumour

\section{Normal tumour Heavy tumour}
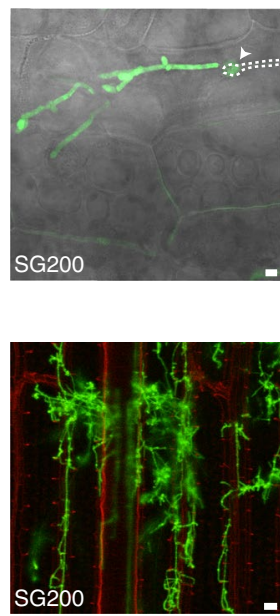
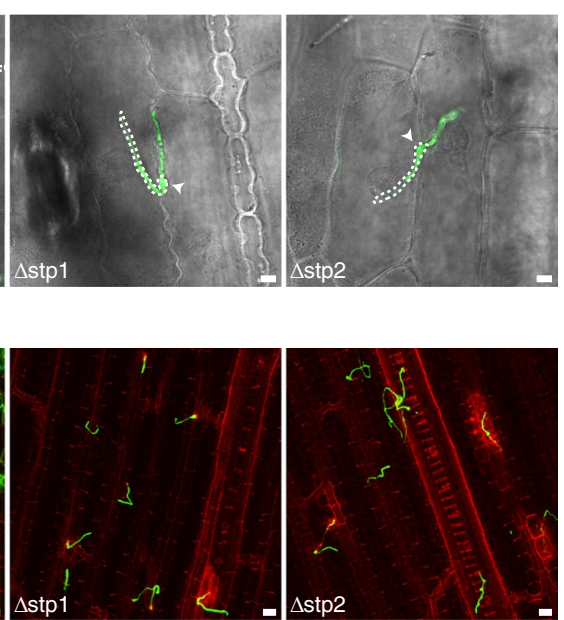
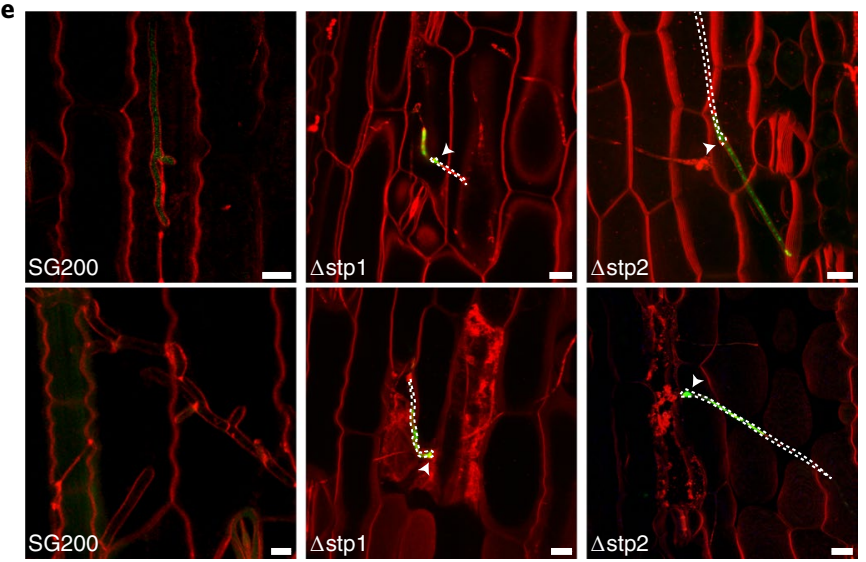

f

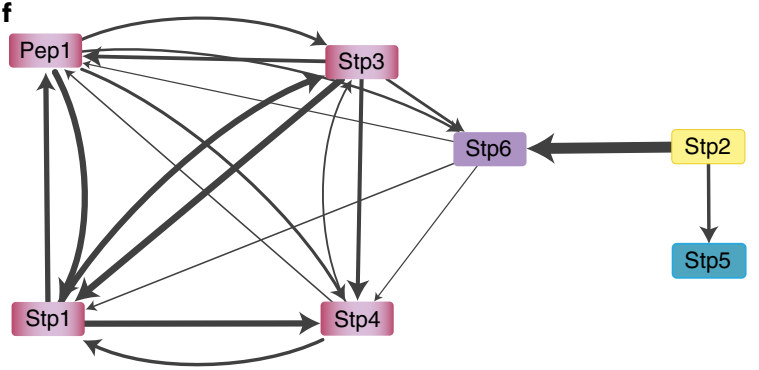

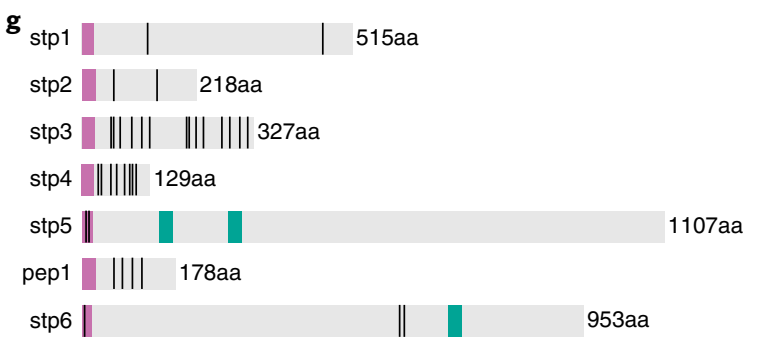

Fig. 1 | Seven U. maydis proteins essential for virulence form a protein complex. a,b, Seven-day-old maize seedlings were infected with SG200 and the indicated deletion strains. At 12 d.p.i., representative leaves were photographed (a) and disease symptoms were scored (b). The vertical dashed line separates two independent sets of experiments. Data represent the mean of $n=3$ biologically independent experiments. Total numbers of infected plants are indicated above the respective columns. c, Maize epidermal cells 1d.p.i. with SG200AN1, SG200AM1 1 stp1 and SG200AN1 stp2 all expressing cytosolic GFP upon plant penetration. The GFP (green) and bright-field (grey) channels are merged. Hyphae on the plant surface are traced in white; untraced hyphae are intracellular. Arrowheads indicate appressoria. Shown are maximum projections of confocal z-stacks. Scale bars, $5 \mu$ m. $\mathbf{d}, \mathrm{Maize}$ leaves 3 d.p.i. with SG200 and the indicated deletion strains stained with WGA-AF488 (fungal cell wall, green) and propidium iodide (plant cell wall, red). Shown are AF488 (green) and propidium iodide (red) channel overlays of confocal z-stack maximum projections. Scale bars, $25 \mu$ m. e, Maize epidermal cells 1d.p.i. (upper panel) and 2 d.p.i. (lower panel) with SG200AN1, SG200AM1 1 stp1 and SG200AN1 sstp2 all expressing cytosolic GFP upon plant penetration. Plasma membranes were stained with FM4-46 (red). Shown are GFP (green) and FM4-46 (red) channel overlays of confocal z-stack maximum projections. Hyphae on the plant surface are traced in white; intracellular hyphae are untraced. Arrowheads indicate appressoria. Scale bars, $10 \mu \mathrm{m}$. f, Effector protein complex interaction network resulting from co-IP/MS experiments using Stp1, Stp2, Stp3, Stp4, Pep1 and Stp6 as bait proteins across several replicated experiments. Line widths illustrate the average number of spectral counts across experiments. $\mathbf{g}$, Domain arrangement of the Stp proteins and calculated molecular weight without signal peptide. Violet, signal peptide; black vertical lines, cysteine residues; green, transmembrane domains predicted based on sequence conservation to membrane domains containing orthologues from other smut fungi (Supplementary Figs. 1-7).

the apoplastic maize peroxidase POX12 (ref. ${ }^{6}$ ). Stp2-HA also co-immunoprecipitated with Stp6 and, in addition, with the as yet uncharacterized U. maydis protein UMAG_04342, termed Stp5. Stp6 and Stp5 orthologues exist in all sequenced smut fungi, and most are predicted to harbour transmembrane domains (Fig. $1 \mathrm{~g}$ and Supplementary Fig. 6,7). Deletion mutants of either stp4, pep1 $\left(\right.$ ref. ${ }^{4}$ ), stp6 or stp5 were unable to cause disease (Fig. 1a,b) and the phenotype could be fully complemented by respective wild-type or
HA-tagged genes (Extended Data Fig. 1b). Microscopic analyses revealed a proliferation arrest after penetration (Extended Data Fig. 1c), very similar to the phenotype of $s t p 1, s t p 2$ and $s t p 3$ mutants (Fig. 1c and Extended Data Fig. 1c). While these experiments were ongoing, stp4 was published as the essential effector $c c e 1$ (ref. ${ }^{24}$ ). Reciprocal co-IP/MS experiments from extracts after infection with strains expressing Stp4-HA, Pep1-HA and Stp6-HA confirmed the presence of a heptameric complex. Consistent co-purification of 
a

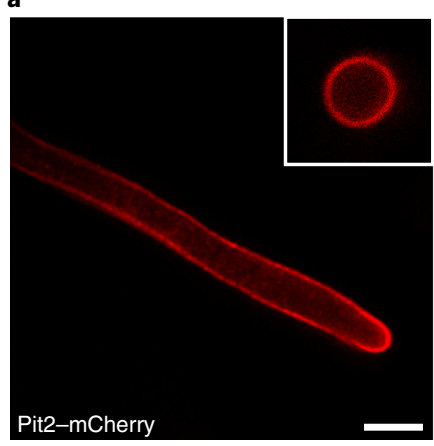

b
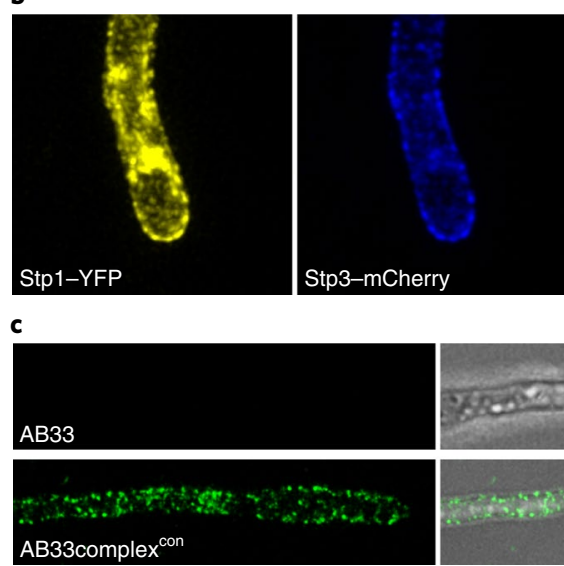
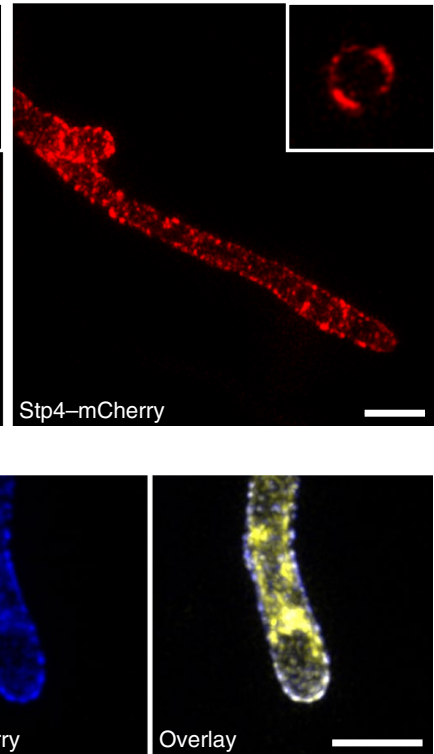

Overlay
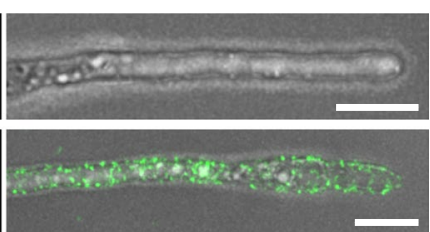

d

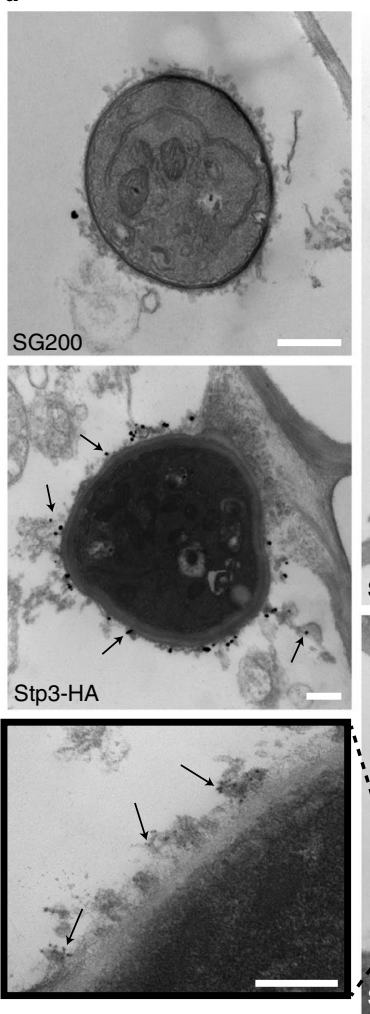

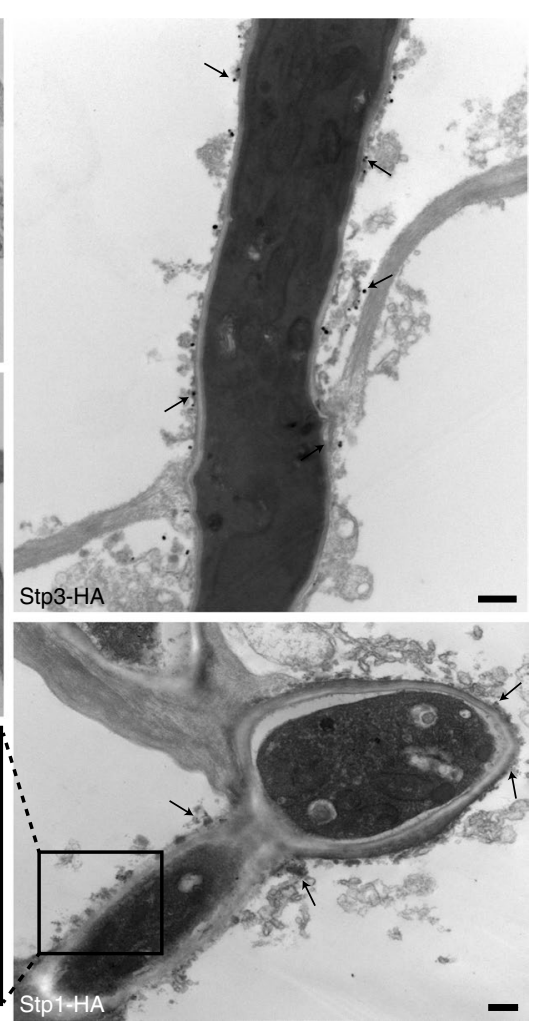

Fig. 2 | The Stp complex localizes to speckles on the surface of fungal hyphae. a, SG200 derived strains expressing the indicated fusion proteins growing in the epidermal layer at 2 d.p.i. mCherry signal, red. Images represent maximum projections of confocal z-stacks. Scale bars, $5 \mu$ m. Insets show cross-sections of fungal hyphae. b. Hyphal tip of SG200 derived strain expressing the indicated fusion proteins growing in the epidermal layer at 2 d.p.i. Yellow fluorescent protein (YFP) signal, yellow; mCherry signal, blue. Signal overlay (white) is shown on the right. Images represent maximum projections of confocal z-stacks. Scale bars, $5 \mu \mathrm{m}$. c, Left panel shows hyphae of AB33complex ${ }^{\text {con }}$ and AB33 immunostained with anti-HA primary antibodies and AF488 conjugated secondary antibody (green) without prior permeabilization. Right panel shows an overlay with differential interference contrast (DIC). Scale bars, $5 \mu \mathrm{m}$. d, Silver-enhanced immunogold labelling of SG200 $\Delta$ stp1-Stp1-HA, SG200 $\Delta$ stp3-Stp3-HA and SG200 in biotrophic hyphae. Transmission electron microscopy images of immunolabelled hyphal tips inside epidermal plant cells. Images confirm specificity of the antibody (no signal in SG200 hypha), and the label is in clusters about $50 \mathrm{~nm}$ across. Arrows indicate labelled particles. Particle size varies with silver enhancement time. Scale bars, $400 \mathrm{~nm}$.

Stp1, Stp3, Stp4, Pep1 and Stp6 as well as Stp2, Stp5 and Stp6 suggests the existence of two sub-complexes with Stp6 present in both protein assemblies (Fig. 1f and Supplementary Data 1). HA-Stp5 could not be enriched in an anti-HA IP, presumably because of inaccessibility of the HA tag, but could be visualized in total extracts (Extended Data Fig. 1f). Except for Stp6-HA, where prominent smaller-than-full-length products likely resulting from processing were detected, the HA fusion proteins had the expected sizes (Fig. $1 \mathrm{~g}$ and Extended Data Fig. 1d,e). The seven complex members differ in size, are unrelated in amino acid sequence (Fig. 1g) and reside in different locations in the genome but appeared co-regulated, showing no expression in axenic culture, strong induction during colonization and an expression peak at 2 d.p.i. (Extended Data Fig. 1g). All complex members were detected in all 11 analysed smut genomes (Supplementary Figs. 1-7). None of the mutants were affected in filamentation or sensitivity to various stresses (Extended Data Fig. 1h,i). This illustrates that the heptameric complex identified here, which we have designated the 'Stp complex', is specifically required during plant colonization.

stp6 has a complex gene structure encoding two mRNAs that are expressed at different levels ${ }^{3}$ and encode both a short N-terminal polypeptide (Stp6s) and a long version (Stp6), with Stp6 predicted to have a single transmembrane domain (Extended Data Fig. 2a-d). stp6 cDNA expressed from the stp6 promoter was able to complement the stp6 deletion phenotype, while stp6s alone was not able to complement it (Extended Data Fig. 2e). Co-IP/MS analysis from tissue infected with a Stp2-HA expressing strain identified peptides covering the entire length of Stp6 (Extended Data Fig. 2g), confirming that Stp6 is a component of the complex. Finding that the effector Pep1 (ref. ${ }^{6}$ ) was now present in the Stp complex raised the possibility that Pep1 might be a dual function effector that acts very early in the apoplast when the peroxidase POX12 is expressed and subsequently acts in the complex. To address this, we tried to separate the two functions by mutational analysis and found that a Pep $1_{\triangle 27-42}$-HA protein lacking 15 amino acids downstream of the signal peptide was unable to interact with POX12 in a yeast two-hybrid assay (Extended Data Fig. 3a-c). The fact that this mutant protein was expressed to similar levels as Pep1-HA and complemented the pep1 mutant phenotype (Extended Data Fig. 3d,e) must therefore reflect the function of Pep1 in the effector complex.

To test whether Stp complex members are secreted, we expressed all HA-tagged Stp proteins from a constitutive promoter. In the supernatants of their respective cultures, Stp1, Stp2, Stp3 and Stp4 proteins could be detected by western blot, while HA-Stp 5 and Stp6-HA could not be detected (Extended Data Fig. 4a-d). Instead, HA-Stp5 and Stp6-HA localized to the fungal plasma membrane fraction (Extended Data Fig. 4e). These results strongly suggest that the Stp complex is anchored in the fungal membrane. 

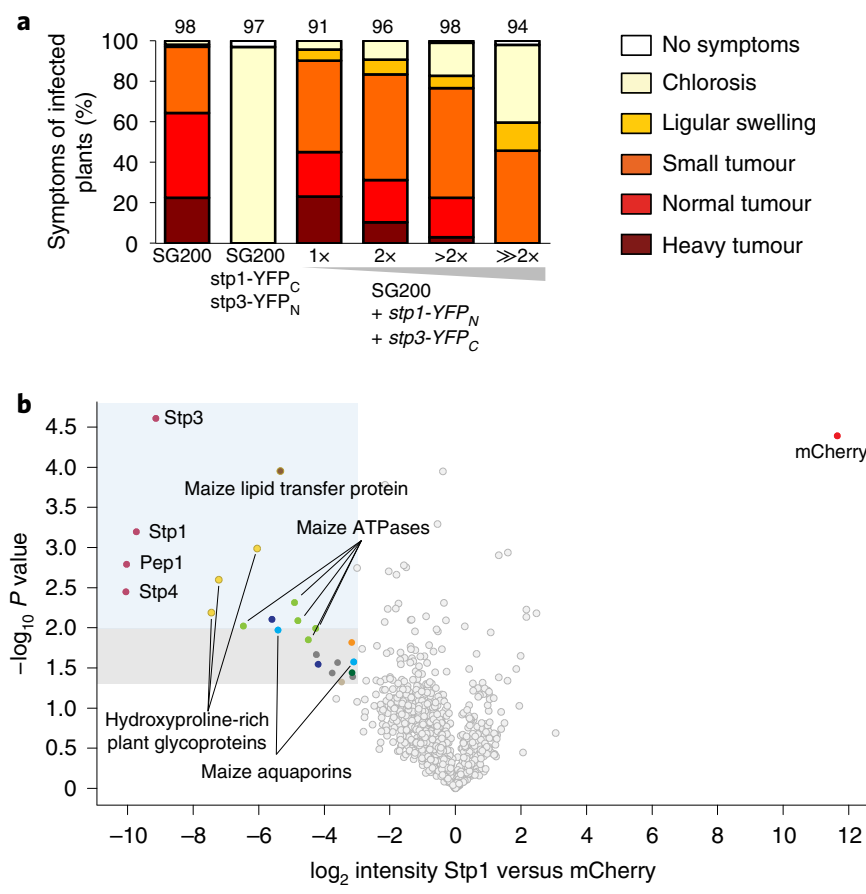

Fig. 3 | Virulence contribution of the Stp complex and plant protein interactors. a, Seven-day-old maize seedlings were infected with the indicated strains. Disease symptoms were scored 12 d.p.i. Strain SG200stp1-YFP ${ }_{C}$ stp3-YFP ${ }_{N}$ expresses indicated BiFC fusion proteins from genes tagged in their native locus. All other columns display SG200 with increasing numbers of ectopic insertions of stp1-YFP $P_{N}$ and stp3-YFP $P_{C}$ in addition to the native untagged copies. All data represent the mean of $n=3$ biologically independent experiments. Total numbers of infected plants are shown above the respective columns. $\mathbf{b}$, Plant interactors of the Stp complex shown by a volcano plot illustrating the $P$ values versus $\log _{2}$ protein abundance ratios between Stp1-HA and mCherry-HA for co-IP/MS experiments, which were performed in biological triplicates with material isolated 3 d.p.i. and extracted with high detergent mix of maize infected with FB1stp1-HA $\times$ FB2stp1-HA. Displayed are all proteins for which at least four peptides were detected. Coloured dots show the indicated proteins. Significance was calculated using Student's $t$-test. The blue- and grey-shaded areas indicate $P$ values $\leq 0.01$ and $\leq 0.05$, respectively, and an $x$-axis value ( $\log _{2}$-intensity difference of $m C h e r r y$ versus Stp 1$)$ below -3 .

To localize the complex members during plant colonization, strains expressing genes for functional mCherryHA fusion proteins under the respective native promoters were constructed (Extended Data Fig. 5a). Except for HAmCherry-Stp5, which was only detected in total extracts (Extended Data Fig. 5b), full-length fusion proteins together with degradation products could be detected (Extended Data Fig. 5c,d). For microscopic analysis, a strain expressing the apoplastic effector Pit2-mCherryHA (ref. ${ }^{7}$ ) served as control. Pit2-mCherryHA was uniformly distributed around biotrophic hyphae (Fig. 2a) while Stp1-mCherryHA, Stp2-mCherryHA, Stp3-mCherryHA, Stp4-mCherryHA, Pep1-mCherryHA and Stp6-mcherryHA all accumulated in speckles (Fig. 2a and Extended Data Fig. 5e). For HAmCherry-Stp5, a weak signal lined the hyphal tips and was detected inside hyphae (Extended Data Fig. 5e), in line with its presumed membrane localization.

To determine whether the speckles contained the complex, we generated a strain expressing both Stp1-HAYFP and Stp3-mCherryHA from their native promoters (Extended Data Fig. 5a). Confocal microscopy detected co-localization of the two fusion proteins in speckles (Fig. 2b). To obtain evidence that the speckles contained the effector complex, we attempted bimolecular fluorescence complementation (BiFC). However, all strains expressing two complex members tagged with the $\mathrm{N}$-terminal domain of YFP and the C-terminal domain of YFP in their respective genomic loci were unable to cause disease (Fig. 3a and Extended Data Fig. 6a,b). This suggested that the complex does not tolerate two complex members with tags that can associate. Given this strong phenotype, we next generated wild-type strains co-expressing Stp1-YFP ${ }_{\mathrm{N}}$ and Stp3-YFP ${ }_{\mathrm{C}}$ in different copy numbers in SG200 (that is, in a context where all untagged complex members are also present). In these strains, virulence decreased concomitantly with integrated copy number (Fig. 3a). This dominant negative phenotype indicates that complex formation is critical for virulence.

To localize Stp1 and Stp3 at higher resolution, immunoelectron microscopy was performed on leaf sections infected with strains expressing HA fusion proteins from their native promoters. Antibody labelling was carried out prior to fixation and thin sectioning of maize leaves, and the only fungal hyphae accessible to the label were those inside plant cells that had been cut open so that plant cytoplasm leaked out. Here, the immunolabel was found outside the hyphal cell wall and in contact with protrusions extending into the plant cell for both Stp1-HA and Stp3-HA. Sometimes the tips of these protrusions appeared attached to membrane chunks/ cell debris (Fig. 2d and Extended Data Fig. 7a). In an untagged SG200 strain, protrusions were seen, but no specific labelling was detected (Fig. 2d). When biotrophic wild-type hyphae were analysed without removal of cytosolic content, electron-dense structures were detected in the interaction zone, similarly to published observations (Extended Data Fig. 7b) ${ }^{25}$. The interaction zone of stp1 mutant hyphae sometimes contained large vesicular structures in proximity of hyphae (Extended Data Fig. 7b), which could reflect attacks by the plant defence system.

Because it is only during the biotrophic interaction that all components of the Stp complex are expressed, we attempted to reconstitute the complex in filaments of the $U$. maydis strain $\mathrm{AB} 33$ by expressing all seven HA-tagged genes under control of different constitutive promoters selected to match the maximum expression levels of the respective genes ${ }^{3}$ after colonization (AB33complex ${ }^{\text {con }}$ ). Unpermeabilized filaments of $\mathrm{AB} 33$ and $\mathrm{AB} 33$ complex $^{\text {con }}$ were subjected to immunolocalization using AF488-coupled secondary HA antibodies. While fluorescent signals appeared in speckles in AB33complex ${ }^{\text {con }}$, AB33 was unlabelled (Fig. 2c). When filaments of these strains and, as an additional control, a derivative of AB33 lacking all complex members except pep1 (AB33 $\Delta 6$ complex) was analysed by scanning electron microscope (SEM), we detected a high density of exposed structures on the surface in AB33complex ${ }^{\text {con }}$, the majority of them small, with some larger ones scattered among them. Such larger structures were also visible in AB33 and AB33 $\Delta 6$ complex, while the small structures appeared to be absent from these strains (Extended Data Fig. 5f). Given these data, it is likely that constitutive expression of the seven complex members allowed the complex to be reconstituted in a surface-exposed structure.

As we failed to detect prominent plant proteins interacting with the complex despite seeing protrusions extending into plant cells, we increased fungal biomass and improved solubilization of membrane proteins with a high detergent buffer that had previously been used successfully to extract the type IVa pilus machine proteins from Myxococcus xanthus ${ }^{26}$. With these adjustments, we identified substantially more spectral counts for Stp1-HA, Stp3, Stp4 and Pep1 after co-IP/MS (Supplementary Data 2). Combining the improved protein extraction procedure with replicated experiments allowed us to perform sensitive label-free quantification (Fig. 3b), making a strong and substantial enrichment of the four complex members evident. Surprisingly, a number of discrete plant proteins, including plasma membrane ATPases and PIP2-type 

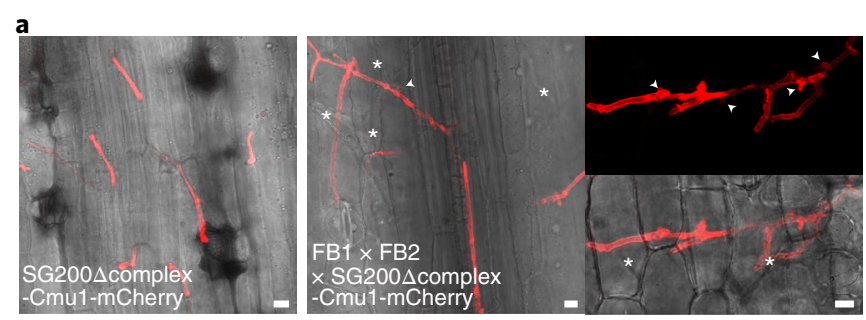

b
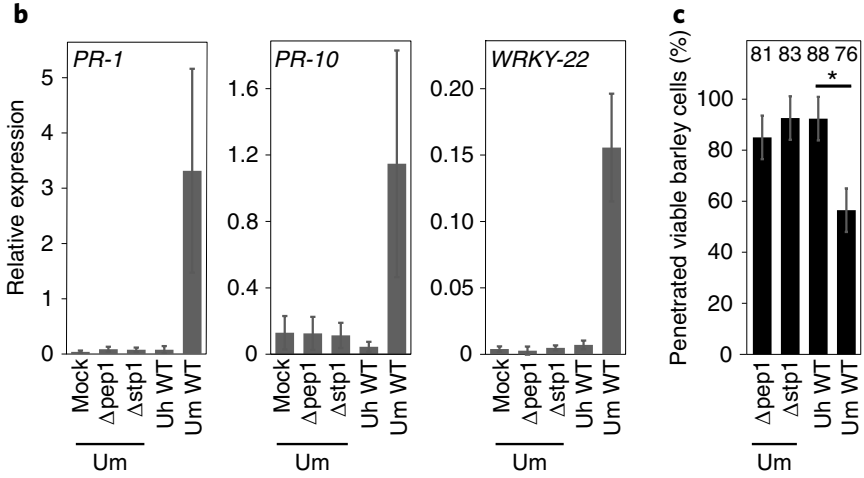

Fig. 4 | Indirect evidence for an involvement of the Stp complex in effector translocation. a, A mutant lacking all seven stp complex genes can be partially rescued by wild-type strains. Plants were co-infected by SG200 $\Delta$ complex-Cmu1-mCherry and a mixture of compatible FB1 $\times$ FB2 wild-type strains. The $\Delta$ complex mutant was visualized by its fluorescence at 2 d.p.i. Clamp connections are indicated by arrowheads, and non-fluorescent hyphae of wild type are labelled with asterisks. Images represent maximum projections of confocal z-stacks. Scale bars, $10 \mu \mathrm{m}$. b, Quantitative real-time PCR of indicated barley defence genes 2 d.p.i. with strains FB1:mock, FB1 $\Delta$ pep1×FB2 $\Delta$ pep1 (Um $\Delta$ pep1), FB1 $\Delta$ stp $1 \times$ FB2 $\Delta$ stp1 (Ums stp1) and compatible Ustilago hordei wild-type strains (UhWT) and FB1 $\times$ FB2 (UmWT) as controls. The vertical axis displays expression values relative to water-infected leaf samples. Data shown are the mean values of relative expression and correspond to $n=5$ biological replicates. Error bars indicate standard deviation. c, Values shown are the mean of penetrated viable barley epidermal cells quantified at 2 d.p.i. after staining with fluorescein diacetate (FDA). The number above each column indicates the total number of cells counted. All experiments were performed in five biological replicates. Error bars indicate standard deviation. Asterisk indicates significance $P=0.0251$, calculated by an unpaired two-sided $t$-test.

aquaporins, a predicted GPI-anchored maize lipid transfer protein and hydroxyproline-rich glycoproteins, also showed elevated levels (Fig. $3 \mathrm{~b}$ and Supplementary Data 3). This indicates that the fungal protein complex might be connected to proteins in the plant plasma membrane.

To address the function of the complex and its critical role in virulence, we considered an involvement in effector delivery, because this would fit with the protrusions extending into host cells and explain the massive defence responses seen when plants are infected with complex mutants. Biotrophic pathogens usually suppress plant cell death very efficiently by secreted effector ${ }^{27,28}$. We were unable to visualize a defect in effector delivery directly and therefore tried to provide indirect evidence for an involvement of the complex. As attempts to suppress the cell death phenotype of complex mutants by chemical intervention were unsuccessful, we performed co-infections of SG200 $\Delta$ complex with a mixture of compatible untagged wild-type strains. SG200 $\Delta$ complex lacks all seven complex members but expresses a Cmu1-mCherry fusion protein and can be distinguished from wild-type cells by its fluorescence. While biotrophic hyphae of SG200 $\Delta$ complex showed the stp phenotype, in co-infections with compatible wild-type

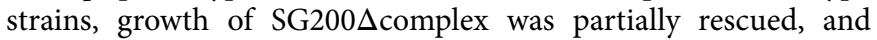
we observed fluorescing hyphae with clamp connections and branches (Fig. 4a). Solopathogenic strains like SG200 are attenuated in mating ${ }^{29}$ and, consequently, neither growth nor virulence of SG200 $\Delta$ complex could be restored in co-infections with haploid FB1 or FB2 strains (Extended Data Fig. 8). In addition, we considered it highly unlikely that complementation of all seven complex components could occur by wild-type cells, which would have to provide the complex proteins in trans. Therefore, this result is a strong indication that wild-type hyphae have successfully downregulated plant defence responses through their arsenal of effectors, and this has allowed the complex mutant to extend its biotrophic growth. The second indirect argument for an involvement of the complex in effector delivery stems from the observation that the induction of non-host resistance is abolished in complex mutants. Non-host resistance is a common immune response likely caused by detection of non-adapted effectors ${ }^{30,31}$. For U. maydis, it has been shown previously that wild-type strains cause non-host resistance in barley and that this is associated with a massive induction of the hypersensitive response marker genes $P R-1, P R-10$ and WRKY-22 and cell death. By contrast, barley infection with $U$. maydis pep1 mutants does not cause this response ${ }^{32}$. As only the peroxidase inhibitor function of Pep1 was known at the time ${ }^{32}$, this latter result was difficult to explain. We have now demonstrated that in addition to pep 1 mutants, stp1 mutants also failed to elicit the expression of the hypersensitive response marker genes and death of penetrated cells (Fig. 4b,c). This can be explained by proposing that the mutants do not deliver the effectors that are recognized in barley.

\section{Discussion}

In this study, we have identified a protein complex of seven proteins critical for the virulence of U. maydis. All seven proteins are present in all analysed smut species, and successful cross-species complementations for Pep1, Stp4 (Cce1) and Stp1 suggest a conserved function of the complex ${ }^{24,33,34}$. Formation of the complex is essential for both suppressing plant defence responses in the compatible situation and triggering non-host resistance, making it likely that the complex is required for the delivery of effectors that both downregulate these responses in host plants and are recognized in the non-host situation. Based on its insensitivity to high detergent concentrations, we believe that the Stp complex represents an ordered complex of structural proteins assembled in as yet unknown stoichiometry, present in many copies in biotrophic hyphae. That we were able to reconstitute the complex in an antibody-accessible form by expressing its seven components constitutively, together with the clustering in speckles similar to the ones seen via fluorescently tagged complex members during plant colonization, suggests a structure that is surface-exposed. Although we do not yet know whether these structures are functional, availability of such a strain will now aid in acquisition of structural data by cryo-electron tomography. The surface-exposed form is also consistent with the immunolocalization data that reveal protrusions extending into host cells. These structures might be similar to vesicular tubular structures seen in previous electron microscopy analyses of smut fungi $i^{35}$ as well as in rust fungi ${ }^{36,37}$. A connection between the fungal complex and the host plasma membrane seems likely given our finding of maize aquaporins and maize plasma membrane ATPase in the detergent-resistant Stp complex. While we presently do not know through which component the complex connects to the plant plasma membrane, interestingly, it has recently been shown that in rice plants, the plant plasma membrane resident aquaporin PIP1;3 and harpin Hpal (a translocator protein of the bacterial pathogen Xanthomonas oryzae pv. oryzae type III secretion system) interact and cooperate in effector translocation ${ }^{37}$. Hence, it is conceivable 
that the Stp complex of $U$. maydis also targets maize aquaporin to facilitate effector delivery. Plant plasma membrane ATPases, the other interactors of the Stp complex, facilitate membrane transport processes $^{38}$ and thus might also promote effector delivery. While bacterial pathogens can use at least eight different systems for effector translocation to host cells ${ }^{39}$, knowledge about effector delivery by eukaryotic pathogens is restricted to apicomplexan parasites. In plasmodium parasites, many translocated effectors carry a characteristic PEXEL motif, which directs them to a distinct endoplasmic reticulum site for processing ${ }^{40,41}$. This step is followed by secretion into the parasitophorous vacuole, from which proteins in their unfolded state are channelled, via a translocon, into the host cell ${ }^{40}$. Fungal translocated effectors lack a common motif, and it is presently unknown how they are selected for delivery. In Magnaporthe oryzae, translocated effectors preferentially accumulate in the biotrophic interfacial complex, a membrane-rich structure of plant origin associated with biotrophic hyphae ${ }^{42}$. In addition, M. oryzae translocated effectors use a novel form of secretion involving exocyst components and the Ssol $t$-SNARE while apoplastic effectors follow the conventional secretory pathway ${ }^{43}$. In U. maydis, the deletion of the exocyst component gene exo70 did not affect virulence (K. Münch and R.K., unpublished observation), suggesting that a different mechanism of effector delivery is used. The finding of the Stp complex in a fungal structure extending into host cells could indicate such a device for effector delivery or the delivery of effectors in vesicles.

The essential role of all complex members in virulence and their conservation in Ustilaginaceae makes the complex a highly promising target for disease intervention. Although the complex currently appears restricted to Ustilaginaceae, we consider it likely that structural insights may reveal features that can then be used to search for related proteins in other fungal species.

\section{Methods}

Strain construction and growth conditions. Strains generated and used in this study are listed in Supplementary Table 1. Information concerning plasmids and how they were generated is found in Supplementary Table 2. The Escherichia coli strains DH5 $\alpha$ (Bethesda Research Laboratories) and TOP10 (Life Technologies) were used for the cloning and amplification of plasmids. Oligonucleotides are listed in Supplementary Table 3.

Deletion mutants were generated by gene replacement using a PCR-based approach $^{44}$. For the integration of genes into the ip locus, plasmids containing a carboxin resistant ip allele $\left(i p^{\mathrm{R}}\right)$ were used ${ }^{45}$. These plasmids were linearized with the restriction enzymes SspI or AgeI and subsequently inserted via homologous recombination in the carboxin-sensitive ip allele $\left(i p^{s}\right)$ of $U$. maydis. If not otherwise indicated, transformed strains carrying a single insertion in the ip locus were generated as previously described ${ }^{46}$. Tagging of endogenous loci was done using CRISPR-Cas9 technology ${ }^{47}$.

U. maydis strains were grown on a rotary shaker $\left(200\right.$ r.p.m.) at $28^{\circ} \mathrm{C}$ in liquid YEPSL medium ( $0.4 \%$ yeast extract, $0.4 \%$ peptone and $2 \%$ sucrose), in CM medium $^{48}$ or on PD solid medium (2.4\% potato dextrose broth and $2 \%$ agar). To test filamentous growth, cell suspensions were spotted on PD-charcoal plates containing $1 \%$ activated charcoal. Stress assays were performed as previously described $^{49}$. Transformation and selection of $U$. maydis transformants followed published procedures ${ }^{18}$. To assess virulence, seven-day-old maize seedlings of the maize variety Early Golden Bantam (Urban Farmer) were syringe-infected as previously described ${ }^{18}$. At least three independent infections were carried out, and disease symptoms were scored according to Kamper et al. ${ }^{18}$

For Sacharomyces cerevisiae two-hybrid interaction studies, strain AH109 (Clontech) was used ${ }^{50}$. Yeast growth, transformation, selection and protein extraction were done according to the Clontech Matchmaker GAL4 Two-Hybrid user manual. To visualize proteins in western blots, mouse anti-HA monoclonal primary antibody (1:5,000 dilution; Sigma-Aldrich), mouse anti-myc monoclonal primary antibody (1:10,000 dilution; Sigma-Aldrich) and anti-mouse lgG secondary antibody (1:10,000 dilution; Cell Signaling Technology) were used.

Staining and microscopy. Plant samples were harvested at the indicated time points and a small piece of leaf tissue was cut from about $1-2 \mathrm{~cm}$ below the infection mark. Either immediately or following staining, tissue pieces were placed on a glass slide in $\mathrm{H}_{2} \mathrm{O}$ prior to confocal microscopy.

To visualize biotrophic hyphae, infected leaf tissue was harvested at 3 d.p.i. and placed into $100 \%$ ethanol to remove the chlorophyll. Fungal hyphae were stained with Alexa Fluor 488 conjugate of wheat germ agglutinin (Invitrogen), and plant cell walls were visualized by staining with propidium iodide (Sigma-Aldrich) as previously described ${ }^{51}$. To stain the plant plasma membrane, infected leaf material was harvested at 1-2 d.p.i. and stained with $0.016 \mathrm{mM}$ FM4-64 (Thermo Fisher) in $\mathrm{H}_{2} \mathrm{O}$ for $1-2 \mathrm{~h}$ at room temperature. To quantify the viability of barley epidermal cells that contained fungal appressoria, a microscopy-based method was used $^{32}$. The experiment was performed in three biological replicates. An unpaired $t$-test was used (GraphPad Software, Inc.; https://www.graphpad.com) to assess statistically relevant differences.

Confocal microscopy was performed using a white light laser Leica TCS SP8x/ WLL confocal laser-scanning microscope (Leica). GFP fluorescence was excited at $488 \mathrm{~nm}$ and detected at $495-530 \mathrm{~nm}$. AF488 was excited at $488 \mathrm{~nm}$ and detected at $506-536 \mathrm{~nm}$. Propidium iodide was excited at $561 \mathrm{~nm}$ and detected at $640-725 \mathrm{~nm}$. FM4-64 was excited at $514 \mathrm{~nm}$ and detected at $623-700 \mathrm{~nm}$. Calcofluor white was excited at $405 \mathrm{~nm}$ and detected at $425-445 \mathrm{~nm}$. FDA was excited at $488 \mathrm{~nm}$ and detected at $495-530 \mathrm{~nm}$. mCherry fluorescence was excited at $585 \mathrm{~nm}$ and detected at $597-635 \mathrm{~nm}$. YFP fluorescence was excited at $514 \mathrm{~nm}$ and detected at 520-550 nm. Detection of mCherry and YFP fluorescence was achieved with a hybrid detector $(\mathrm{HyD})$ where the detection time was gated (between 0.3 and 6.0 nanoseconds) after the excitation laser pulse. For image deconvolution, the HyVolution software package (Leica and Scientific Volume Imaging B.V.) was used with the highest resolution settings. Image data were processed using the Leica Application Suite X v.3.1.5. Confocal images are representative of at least three biological replicates yielding similar results.

To visualize the reconstituted complex in the filaments of AB33, the strains were shifted to the filamentous form as described previously ${ }^{52}$. For SEM, shifted cells were spotted on a membrane (Hybond-N+, GE Healthcare) placed on a nitrate-minimal-agar plate and kept at $28^{\circ} \mathrm{C}$ for several hours. Specimens were then fixed in $4 \%$ glutaraldehyde in Sörensen buffer $\mathrm{pH} 7.8$ overnight before being washed six times with distilled water for $10 \mathrm{~min}$ each. Then, the specimens were washed a further six times, for $10 \mathrm{~min}$ each time, with water-acetone mixtures with increasing percentages of acetone $(30,50,75,90,95$ and $100 \%$; the last step was repeated twice). Specimens were critical point dried (Polaron E 3000), fixed on stubs with electrically conducting adhesive pads and sputter coated (Balzers Union) with gold. Specimens were observed with a Hitachi S-530 SEM at $25 \mathrm{kV}$. For immunolocalization, the staining was performed according to Ma et al. ${ }^{10}$ The shifted cells were washed with PBS, blocked in 3\% BSA and subsequently incubated in PBS containing mouse anti-HA antibody (1:1,500 dilution; SigmaAldrich) and $3 \%$ BSA at $4{ }^{\circ} \mathrm{C}$ overnight. The cells were washed three times with PBS and incubated in PBS containing goat anti-mouse IgG secondary antibody conjugated with Alexa Fluor 488 (1:15,000 dilution; Life Technologies) for $1 \mathrm{~h}$ at room temperature. After washing three times with PBS, the cells were analysed by confocal laser-scanning microscopy. Images are representative of at least three biological replicates yielding similar results.

For immuno-transmission electron microscopy, cross-sections of maize leaves were cut 36-48 hours after they had been inoculated with $U$. maydis strains expressing Stp3-HA or Stp1-HA from their respective native promoters. The HA-tagged proteins were localized prior to resin embedment and sectioning for electron microscopy, adapting the technique described by Sesack et al..$^{53}$. Briefly, sections were fixed in $0.5 \%$ glutaraldehyde and $4 \%$ freshly prepared formaldehyde in pH 7.4 phosphate buffer for $30 \mathrm{~min}$, rinsed, blocked and labelled with the primary antibody (1:60 dilution; HA tag monoclonal antibody 2-2.2.14, Invitrogen) in blocking buffer for $8 \mathrm{~h}$. After rinsing, leaf pieces were incubated overnight in secondary antibody conjugated to ultra-small gold (1:50 dilution; Electron Microscopy Sciences). After rinsing, leaf pieces were fixed in $2 \%$ glutaraldehyde in pH 7.4 phosphate buffer for $15 \mathrm{~min}$. The small gold particles were then enhanced with silver, using methods and reagents as provided in the Aurion R-Gent Silver Enhancement kit (AURION Immuno Gold Reagents \& Accessories). Only maize cells that were cut open in preparation could be labelled, because the antibodies and silver enhancement reagents did not penetrate intact plant cell walls. After enhancement, sections were briefly postfixed in osmium tetroxide, dehydrated, infiltrated and embedded in Ultrabed Low Viscosity resin (Electron Microscopy Sciences). Longer enhancement and osmication times favoured larger particle size and better membrane visualization, but shorter times favoured retention of the silver-enhanced particles. Sectioning and imaging were performed as described elsewhere ${ }^{54}$. Images are representative of at least two independent experimental replicates yielding similar results.

Protein extraction and co-IP from infected plant material. For co-IPs, samples were harvested by excising infected plant parts and shock freezing in liquid nitrogen before being stored at $-80^{\circ} \mathrm{C}$. Frozen plant material was ground to a fine powder using a prechilled mortar and pestle or a Retsch CryoMill. For protein extraction, $1 \mathrm{~g}$ of frozen powder was added to a prechilled mortar containing $4 \mathrm{ml}$ of ice-cold HNN lysis buffer and approximately $100 \mu \mathrm{l}$ of $0.1 \mathrm{~mm}$ silica spheres (Lysing Matrix B, Bulk MP Biomedicals). HNN lysis buffer $(50 \mathrm{mM}$ HEPES pH 7.5, $150 \mathrm{mM} \mathrm{NaCl}, 50 \mathrm{mM}$ NaF, $5 \mathrm{mM}$ EDTA, $0.1 \% \mathrm{NP}-40$ and $1 \%$ polyvinylpyrrolidone). Prior to use, one tablet of cOmplete (Mini Protease Inhibitor, Merck) was added to $50 \mathrm{ml}$ of HNN lysis buffer. After being ground in buffer with a chilled pestle, samples were transferred to fresh $5 \mathrm{ml}$ tubes and 
incubated on ice for $30 \mathrm{~min}$. After incubation, samples were centrifuged at $4{ }^{\circ} \mathrm{C}$ for $15 \mathrm{~min}$ at $20,000 \mathrm{~g}$, and the resulting supernatant was transferred to a fresh tube. After adding $12 \mu \mathrm{l}$ of magnetic beads (Pierce Anti-HA magnetic beads, Thermo Fisher Scientific), the samples were incubated for $1 \mathrm{~h}$ at $4^{\circ} \mathrm{C}$ with rotation. The magnetic beads were separated on a magnetic separator. In experiments using the detergent-rich buffer, $1 \mathrm{~g}$ of ground powder was transferred to $2 \mathrm{ml}$ of the detergent-rich buffer (50 mM HEPES pH 7.5, $150 \mathrm{mM} \mathrm{NaCl}, 50 \mathrm{mM} \mathrm{NaF}$, 5 mM EDTA, 1\% polyvinylpyrrolidone, 4\% CHAPS, 4\% Zwittergent 3-14, 4\% $\mathrm{N}$-lauroylsarcosine, $0.05 \% \mathrm{NP}-40$ and $20 \%$ glycerol), to $50 \mathrm{ml}$ of which one tablet of cOmplete (Mini Protease Inhibitor, Merck) was added, and incubated for $10 \mathrm{~min}$ at room temperature. Afterwards, the solution was diluted 1:6 with $\mathrm{HNN}$ to reduce all detergent to less than $1 \%$, then was incubated for $1 \mathrm{~h}$ at $4{ }^{\circ} \mathrm{C}$. The subsequent steps were identical to those for samples prepared in HNN buffer.

IPs followed by western blots were done with HNN lysis buffer, skipping the second grinding step. The antibodies used were rabbit anti-HA primary antibody (1:10,000 dilution; Sigma-Aldrich) and anti-rabbit lgG secondary antibody (1:10,000 dilution; Cell Signaling Technology).

Identification of proteins by liquid chromatography-mass spectrometry (LCMS). Sample preparation of purified proteins and LC-MS proteomics analysis were performed as described previously, with minor modifications ${ }^{55}$. In brief, an on-bead tryptic digest (Mass Spectrometry Grade Trypsin, Promega) was carried out on protein enrichments with subsequent reverse-phase $\mathrm{C} 18$ solid phase extraction using Minispin columns (Harvard Apparatus). Peptides eluted from the spin columns were dried, reconstituted in $0.1 \%$ trifluoroacetic acid and subjected to LC-MS analysis.

LC-MS analysis of the peptide samples was carried out on a Q-Exactive Plus instrument in conjunction with an Ultimate 3000 RSLC nano and a nanospray flex ion source (all Thermo Fischer Scientific). A $42 \mathrm{~cm}$ self-packed C18 column was used for peptide separation using a 2-35\% acetonitrile gradient prior to the Orbitrap-MS analysis. The MS analysis was performed using settings identical to those described by Gómez-Santos et al. ${ }^{55}$.

For the database search, the combined protein database for U. maydis and Zea mays downloaded from Uniprot (https://www.uniprot.org) was used. Spectral counting based analysis was performed using MASCOT v.2.5 executed from the Proteome Discoverer platform v.1.4 (Thermo Scientific). The following search parameters were used: full tryptic specificity required (cleavage after lysine or arginine residues), two missed cleavages allowed, carbamidomethylation (C) set as a fixed modification and oxidation $(\mathrm{M})$ and deamidation $(\mathrm{N}, \mathrm{Q})$ set as a variable modification. The mass tolerance was set to $10 \mathrm{ppm}$ for precursor ions and $0.02 \mathrm{Da}$ for high energy-collision dissociation (HCD) fragment ions. The results were then imported into Scaffold v.4.6.2 (Proteome Software), and a $1 \%$ false discovery rate was adjusted within the Scaffold software.

Twenty bait purifications $(3 \times$ Stp1-HA, $3 \times$ Stp2-HA, $3 \times$ Pep1-HA, $3 \times$ Stp6-HA, $4 \times$ Stp3-HA and $4 \times$ Stp4HA) versus an equal number of control experiments were used to detect a set of specifically bait-interacting proteins. Protein spectral counts from identified interactors were extracted and ' 0 ' spectral counts were replaced with the background value of 0.5 , then $\log _{2}$ ratios of spectral counts were calculated between baits and mCherry control IPs. The log ratio values were then $z$ transformed. In order to identify potential protein interactors, proteins enriched in a bait purification required a minimum $Z$-score of 2 in at least three experiments for each bait, the only exception being Stp6, which showed slightly higher variations. For Stp6 IP experiments, proteins were considered enriched when a minimum $Z$-score of 2 was detected in two out of three replicate experiments. The $U$. maydis effector protein components surviving the described filtering criteria were visualized in Cytoscape v.3.3.0. Average spectral counts of identified complex members across experiments are represented by edge width.

Label-free quantification (LFQ) of the samples was performed using MaxQuant v.1.6.3.4. For Andromeda database searches, the forward protein databases for $U$. maydis and $Z$. mays obtained from Uniprot were used. The search was carried out using full tryptic specificity while allowing two missed cleavages. Carbamidomethylation (C) was set as fixed modification; oxidation (M) and deamidation $(\mathrm{N}, \mathrm{Q})$ as variable modification. MaxQuant was operated with default settings. To calculate protein enrichment in co-IP experiments, MaxQuant-LFQ values were loaded into Perseus v.1.5.2.6 (ref. ${ }^{56}$ ). As a basis for log ratio calculation between the conditions, missing values were imputed using the imputation function from normal distribution implemented in Perseus with default settings (width, 0.3; down-shift, 1.8).

RACE PCR. Total RNA was extracted from leaves infected with SG200 and harvested 3 d.p.i. using TRIzol reagent (Invitrogen). The 3' RACE System for Rapid Amplification of cDNA Ends (Invitrogen) was used to perform 3' RACE PCR. cDNA was prepared using $5 \mu$ g total RNA and the adapter primer (AP) provided in the kit. The first $3^{\prime}$ RACE PCR was performed on the CDNA using primer pairs oCG57 and AUAP and the following reaction conditions: $5 \mathrm{~min}$ at $98^{\circ} \mathrm{C}$ followed by 35 cycles of the sequence $10 \mathrm{~s}$ at $98^{\circ} \mathrm{C}, 30 \mathrm{~s}$ at $59^{\circ} \mathrm{C}, 3 \mathrm{~min}$ at $72^{\circ} \mathrm{C}$ and $5 \mathrm{~min}$ at $72^{\circ} \mathrm{C}$. Then, $1 \mu \mathrm{l}$ of product was used as a template for nested PCR using oligonucleotides oCG63/AUAP and Phusion DNA polymerase (Invitrogen) and the following reaction conditions: $5 \mathrm{~min}$ at $98^{\circ} \mathrm{C}$ followed by 35 cycles of the sequence $10 \mathrm{~s}$ at $98^{\circ} \mathrm{C}, 30 \mathrm{~s}$ at $61^{\circ} \mathrm{C}, 3 \mathrm{~min}$ at $72^{\circ} \mathrm{C}$ and $5 \mathrm{~min}$ at $72^{\circ} \mathrm{C}$. This yielded two products, one $3 \mathrm{kilobase}(\mathrm{kb})$ product and one $1.6 \mathrm{~kb}$ product. The $1.6-\mathrm{kb}$ product could be sequenced and was shown to correspond to the polyadenylated product of stp6s after sequencing with oligonucleotide oCG65. To determine the nature of the larger fragment, PCR reactions were also performed on cDNA using primer pair oCG57/oCG62, revealing a 2.8 -kb product corresponding to a region of stp 6 containing three introns. To determine the structure of the $3^{\prime}$ part of stp6, the $3^{\prime}$ RACE PCR was repeated on cDNA with primer pair oCG47/AUAP. Reaction conditions were $5 \mathrm{~min}$ at $98^{\circ} \mathrm{C}$ followed by $35 \mathrm{cycles}$ of $10 \mathrm{~s}$ at $98^{\circ} \mathrm{C}, 30 \mathrm{~s}$ at $67^{\circ} \mathrm{C}, 35 \mathrm{~s}$ at $72^{\circ} \mathrm{C}$ and $5 \mathrm{~min}$ at $72^{\circ} \mathrm{C}$. The products were used as a template for a nested PCR with primers oCG71/AUAP, yielding a 1.2-kb fragment that could be sequenced using primer oCG71. This fragment contained the $3^{\prime}$ end of stp6, including the polyA tail after nucleotide 3361 .

Visualizing secretion and membrane localization of Stp proteins. To visualize secretion of Stp2-HA, Stp3-HA and Stp4-HA, AB33-derived strains expressing the respective genes constitutively from the otef promoter were generated and shifted to the filamentous form following published procedures ${ }^{52}$. The formation of $b$ filaments was followed microscopically. Cultures were centrifuged $6 \mathrm{~h}$ after the shift, and cell pellets were kept at $-20^{\circ} \mathrm{C}$. For western blot analysis, pellets were resuspended in sample buffer (50 mM Na-HEPES pH 7.5, $200 \mathrm{mM}$ sodium acetate pH 7.5, $1 \mathrm{mM}$ EDTA, $1 \mathrm{mM}$ EGTA, $5 \mathrm{mM}$ magnesium acetate, $5 \%$ glycerol, $0.25 \%$ NP-40, $3 \mathrm{mM}$ DTT and $1 \mathrm{mM}$ PMSF). Prior to use, one tablet of cOmplete (Mini Protease Inhibitor, Merck) was added to $50 \mathrm{ml}$ of the suspension. Cells were disrupted using a Fast Prep-24 Instrument (MP Biomedicals), boiled for 5 min and centrifuged for $1 \mathrm{~min}$ at 13,000 r.p.m. at room temperature. To analyse supernatant fractions by western blot, trichloroacetic acid was added to a final concentration of $20 \%$ to cell-free supernatants from the initial centrifugation. Samples were kept overnight at $4^{\circ} \mathrm{C}$ and then centrifuged at 8,000 r.p.m. for $2 \mathrm{~h}$ at $4^{\circ} \mathrm{C}$. Pellets were washed in $2 \mathrm{ml}$ ice-cold acetone and transferred to a $5 \mathrm{ml}$ microcentrifuge tube. After three additional washes with $5 \mathrm{ml}$ of ice-cold acetone, pellets were dried at $60^{\circ} \mathrm{C}$, resuspended in $40 \mu \mathrm{l}$ of sample buffer and subjected to western blot analysis. For HA protein fusion detection, rabbit anti-HA primary antibody $(1: 10,000$ dilution; Sigma-Aldrich) and anti-rabbit lgG secondary antibody (1:10,000 dilution; Cell Signaling Technology) were used. For lysis control, anti- $\alpha$-tubulin monoclonal primary antibody from mouse (1:2,000 dilution; Calbiochem) and anti-mouse lgG secondary antibody (1:10,000 dilution; Cell Signaling Technology) were used.

For SG200Potef-HA-Stp5, SG200Potef-Stp6-HA and SG200_kex2-Stp1-HA expressing the respective genes from the constitutive otef promoter cells and were propagated to an optical density at $600 \mathrm{~nm}\left(\mathrm{OD}_{600}\right)$ of 0.8 in $\mathrm{CM}(2 \%$ glucose $)$ to which one tablet of cOmplete (Mini Protease Inhibitor, Merck) was added per $50 \mathrm{ml}$. Proteins in the pellet fraction as well as in the supernatant were isolated as described for AB33-derived strains.

To visualize membrane localization of Stp5 and Stp6, SG200Potef-HA-Stp5 and SG200Potef-Stp6-HA were grown in YEPSL until an $\mathrm{OD}_{600}$ of 0.8 and fractionated into a supernatant fraction containing soluble proteins and a plasma membrane containing the pellet fraction, as previously described ${ }^{57}$. The pellet fraction was resuspended in $10 \mathrm{ml}$ of extraction buffer to which both Triton X-100 and SDS were added to final concentrations of $2 \%$. The suspension was kept on ice for $30 \mathrm{~min}$ and centrifuged at 22,000 r.p.m. for $10 \mathrm{~min}$ at $4{ }^{\circ} \mathrm{C}$ to yield a supernatant fraction containing solubilized membrane proteins.

PR gene expression upon non-host infection. For the analysis of PR gene expression, barley plants of the variety Golden Promise were cultivated in a phytochamber at $60 \%$ relative humidity with a $16 \mathrm{~h}$ light period $\left(22^{\circ} \mathrm{C}, 30,000\right.$ lux) and $8 \mathrm{~h}$ dark period $\left(18^{\circ} \mathrm{C}\right)$. For barley infections, U. maydis cultures were grown at $28^{\circ} \mathrm{C}$ and $U$. hordei (4857-4 Mat-1 and 4857-5 Mat-2) cultures were grown at $22^{\circ} \mathrm{C}$ to an $\mathrm{OD}_{600}$ of $0.8-1.5$. Cells were harvested for $10 \mathrm{~min}$ at $1,000 \mathrm{~g}$ and resuspended in $0.1 \%$ Tween 20 to an $\mathrm{OD}_{600}$ of 3 . Next, $300 \mu \mathrm{l}$ of 1:1 mixtures of the respective compatible strains were needle-inoculated into the base of leaf whorls of 11-day-old barley seedlings using a syringe. At $48 \mathrm{~h}$ post infection, leaf sections from $2 \mathrm{~cm}$ below the infection holes to the beginning of the leaf sheet were excised from the second and third leaves from 13 plants, combined, frozen in liquid nitrogen and ground to a fine powder with a mortar and pestle cooled in liquid nitrogen. RNA extraction and RT-qPCR of HvPR1, HvPR19, HvWRKY22 and HvGAPDH were carried out as previously described ${ }^{32}$. The experiment was done in five biological and two technical replicates, and gene expression levels were calculated relative to the expression levels of the constitutively expressed barley glyceraldehyde dehydrogenase gene and the target gene expression level in water-infected plants using the $\Delta \Delta$ Ct method $^{58}$.

Data and bioinformatic analyses. Microsoft Excel 2013 was used for data analysis. For genomes lacking annotations, amino acid sequences were extracted with the program CLC benchtop by tBlastn blast of the genome sequence data using the respective $U$. maydis or the $U$. hordei (barley) protein as a reference and the program CLC genomics workbench (Qiagen v.9.5.3) in combination with the Augustus gene prediction program (http://bioinf.uni-greifswald.de/augustus/) 59 . Protein and DNA sequences of stp orthologues from 11 sequenced smuts 
were derived from the following sources: Ustilago esculenta accession number JTLW00000000, version JTLW01000000 (ref. ${ }^{60}$ ); Ustilago trichophora RK089 accession number LVYE00000000, version LVYE01000000 (ref. ${ }^{61}$ ); Ustilago tritici accession number NSHH00000000, version NSHH01000000 (ref. ${ }^{62}$ ); Sporisorium reilianum f.sp. zeae SRZ2 accession number FQ311430-FQ311474 (ref. ${ }^{63}$ ), Sporisorium reilianum f.sp. reilianum SRS1_H2-8 accession number LT795054-LT795076 (refs. ${ }^{64,65}$ ), Sporisorium scitamineum Sscl8 accession number LK056649-LK056695 (ref. ${ }^{66}$ ); U. maydis 521, https://mycocosm.jgi.doe.gov/ Ustma2_2/Ustma2_2.home.html (ref. ${ }^{18}$ ); U. hordei Uhor01 accession number NSDP00000000 version NSDP01000000 (ref. ${ }^{62}$ ); U. hordei Uh4875-4 accession number CAGI01000001-CAGI01000713 (ref. ${ }^{67}$ ); Ustilago bromivora UB2112 accession number PRJEB7751 (ref. ${ }^{68}$ ); M. pennsylvanicum Mp4 project accession number PRJEB4565, accession number HG529494-HG529928 (ref. ${ }^{69}$ ).

M. pennsylvanicum Mp4 was resequenced by PacBio and gene information from this project was included (R.K., unpublished)

Nucleotide sequences were aligned using Clustal Omega provided by the Swiss Institute of Bioinformatics (https://www.ebi.ac.uk/Tools/msa/clustalo/) ${ }^{70}$, and the multiple nucleotide alignment file was processed with BOXSHADE v.3.21 provided by the EMBnet (https://embnet.vital-it.ch/software/BOX_form.html). Signal peptide prediction was performed with SignalP v.5 (http://www.cbs.dtu.dk/ services/SignalP $/)^{71}$. The occurrence of transmembrane domains was predicted using TMHMM v.2.0 (http://www.cbs.dtu.dk/services/TMHMM/) ${ }^{72}$.

Reporting Summary. Further information on research design is available in the Nature Research Reporting Summary linked to this article.

\section{Data availability}

$U$. maydis genes and encoding protein sequences are available at NCBI under the following accession numbers: $U$. maydis stp1 (UMAG_02475), XP_011388756.1; U. maydis stp2 (UMAG_10067), XP_011388794.1; U. maydis stp3 (UMAG_00715), XP_011386505.1; U. maydis stp4(UMAG_12197), XP_011389576.1; U. maydis pep1 (UMAG_01987), XP_011387901.1; U. maydis stp5(UMAG_04342), XP_011391052.1; U. maydis stp6(UMAG_01695), XP_011387671.1. Source data are provided with this paper.

Received: 1 February 2021; Accepted: 24 March 2021;

Published online: 3 May 2021

\section{References}

1. Fisher, M. C. et al. Emerging fungal threats to animal, plant and ecosystem health. Nature 484, 186-194 (2012).

2. Snetselaar, K. \& Mims, C. Infection of maize stigmas by Ustilago maydis: light and electron microscopy. Phytopathology 83, 843-850 (1993).

3. Lanver, D. et al. The biotrophic development of Ustilago maydis studied by RNA-Seq analysis. Plant Cell 30, 300-323 (2018).

4. Doehlemann, G. et al. Pep1, a secreted effector protein of Ustilago maydis, is required for successful invasion of plant cells. PLoS Pathog. 5, e1000290 (2009).

5. Djamei, A. et al. Metabolic priming by a secreted fungal effector. Nature 478, 395-398 (2011).

6. Hemetsberger, C., Herrberger, C., Zechmann, B., Hillmer, M. \& Doehlemann, G. The Ustilago maydis effector Pep1 suppresses plant immunity by inhibition of host peroxidase activity. PLoS Pathog. 8, e1002684 (2012).

7. Mueller, A. N., Ziemann, S., Treitschke, S., Assmann, D. \& Doehlemann, G. Compatibility in the Ustilago maydis-maize interaction requires inhibition of host cysteine proteases by the fungal effector Pit2. PLoS Pathog. 9, e1003177 (2013)

8. Tanaka, S. et al. A secreted Ustilago maydis effector promotes virulence by targeting anthocyanin biosynthesis in maize. eLife 3, e01355 (2014).

9. Redkar, A. et al. A secreted effector protein of Ustilago maydis guides maize leaf cells to form tumors. Plant Cell 27, 1332-1351 (2015).

10. Ma, L. S. et al. The Ustilago maydis repetitive effector Rsp3 blocks the antifungal activity of mannose-binding maize proteins. Nat. Commun. 9, 1711 (2018).

11. Han, X. et al. A kiwellin disarms the metabolic activity of a secreted fungal virulence factor. Nature 565, 650-653 (2019).

12. Lanver, D. et al. Ustilago maydis effectors and their impact on virulence. Nat. Rev. Microbiol. 15, 409 (2017).

13. Redkar, A., Matei, A. \& Doehlemann, G. Insights into host cell modulation and induction of new cells by the corn smut Ustilago maydis. Front. Plant Sci. 8, 899 (2017).

14. Schmitz, L., McCotter, S., Kretschmer, M., Kronstad, J. W. \& Heimel, K. Transcripts and tumors: regulatory and metabolic programming during biotrophic phytopathogenesis. F1000Res. 7, 1812 (2018).

15. Lo Presti, L. \& Kahmann, R. How filamentous plant pathogen effectors are translocated to host cells. Curr. Opin. Plant Biol. 38, 19-24 (2017).

16. Khan, M., Seto, D., Subramaniam, R. \& Desveaux, D. Oh, the places they'll go! A survey of phytopathogen effectors and their host targets. Plant J. 93, 651-663 (2018).
17. Lanver, D. et al. Plant surface cues prime Ustilago maydis for biotrophic development. PLoS Pathog. 10, e1004272 (2014).

18. Kamper, J. et al. Insights from the genome of the biotrophic fungal plant pathogen Ustilago maydis. Nature 444, 97-101 (2006).

19. Schipper, K. Charakterisierung eines Ustilago maydis Genclusters, das für drei neuartige sekretierte Effektoren kodiert. PhD thesis, Philipps-Universität Marburg (2009).

20. Mendoza-Mendoza, A. et al. Physical-chemical plant-derived signals induce differentiation in Ustilago maydis. Mol. Microbiol. 71, 895-911 (2009).

21. Dickman, M., Williams, B., Li, Y., de Figueiredo, P. \& Wolpert, T. Reassessing apoptosis in plants. Nat. Plants 3, 773-779 (2017).

22. Kabbage, M., Kessens, R., Bartholomay, L. C. \& Williams, B. The life and death of a plant cell. Annu. Rev. Plant Biol. 68, 375-404 (2017).

23. Ustun, S., Hafren, A. \& Hofius, D. Autophagy as a mediator of life and death in plants. Curr. Opin. Plant Biol. 40, 122-130 (2017).

24. Seitner, D., Uhse, S., Gallei, M. \& Djamei, A. The core effector Ccel is required for early infection of maize by Ustilago maydis. Mol. Plant Pathol. 19, 2277-2287 (2018).

25. Snetselaar, K. M. \& Mims, C. W. Sporidial fusion and infection of maize seedlings by the smut fungus Ustilago maydis. Mycologia 84, 193-203 (1992).

26. Treuner-Lange, A. et al. PilY1 and minor pilins form a complex priming the type IVa pilus in Myxococcus xanthus. Nat. Commun. 11, 1-14 (2020).

27. Oliveira-Garcia, E. \& Valent, B. How eukaryotic filamentous pathogens evade plant recognition. Curr. Opin. Microbiol. 26, 92-101 (2015).

28. Matei, A. \& Doehlemann, G. Cell biology of corn smut disease-Ustilago maydis as a model for biotrophic interactions. Curr. Opin. Microbiol. 34, 60-66 (2016).

29. Laity, C., Giasson, L., Campbell, R. \& Kronstad, J. Heterozygosity at the $b$ mating-type locus attenuates fusion in Ustilago maydis. Curr. Genet. 27, 451-459 (1995).

30. Ayliffe, M. \& Sorensen, C. K. Plant nonhost resistance: paradigms and new environments. Curr. Opin. Plant Biol. 50, 104-113 (2019).

31. Stam, R., Mantelin, S., McLellan, H. \& Thilliez, G. The role of effectors in nonhost resistance to filamentous plant pathogens. Front. Plant Sci. 5, 582 (2014).

32. Hof, A., Zechmann, B., Schwammbach, D., Huckelhoven, R. \& Doehlemann, G. Alternative cell death mechanisms determine epidermal resistance in incompatible barley-Ustilago interactions. Mol. Plant Microbe Interact. 27, 403-414 (2014)

33. Hemetsberger, C. et al. The fungal core effector Pep1 is conserved across smuts of dicots and monocots. New Phytol. 206, 1116-1126 (2015).

34. Liang, L. The Role of Stp1, a Secreted Effector, in the Biotrophic Interaction of Ustilago maydis and its Host Plant Maize. PhD thesis, Philipps-Universität Marburg (2013).

35. Bauer, R., Oberwinkler, F. \& Vánky, K. Ultrastructural markers and systematics in smut fungi and allied taxa. Can. J. Bot. 75, 1273-1314 (1997).

36. Mims, C., Rodriguez-Lother, C. \& Richardson, E. Ultrastructure of the host-pathogen interface in daylily leaves infected by the rust fungus Puccinia hemerocallidis. Protoplasma 219, 221-226 (2002).

37. Li, P. et al. Rice aquaporin PIP1;3 and harpin Hpal of bacterial blight pathogen cooperate in a type III effector translocation. J. Exp. Bot. 70 , 3057-3073 (2019).

38. Elmore, J. M. \& Coaker, G. The role of the plasma membrane $\mathrm{H}^{+}$-ATPase in plant-microbe interactions. Mol. Plant 4, 416-427 (2011).

39. Rapisarda, C. \& Fronzes, R. Secretion systems used by bacteria to subvert host functions. Curr. Opin. Plant Biol. 25, 1-42 (2018).

40. de Koning-Ward, T. F., Dixon, M. W., Tilley, L. \& Gilson, P. R. Plasmodium species: master renovators of their host cells. Nat. Rev. Microbiol. 14, 494-507 (2016).

41. Marapana, D. S. et al. Plasmepsin V cleaves malaria effector proteins in a distinct endoplasmic reticulum translocation interactome for export to the erythrocyte. Nat. Microbiol. 3, 1010-1022 (2018).

42. Khang, C. H. et al. Translocation of Magnaporthe oryzae effectors into rice cells and their subsequent cell-to-cell movement. Plant Cell 22, 1388-1403 (2010).

43. Giraldo, M. C. et al. Two distinct secretion systems facilitate tissue invasion by the rice blast fungus Magnaporthe oryzae. Nat. Commun. 4, 1996 (2013).

44. Kamper, J. A PCR-based system for highly efficient generation of gene replacement mutants in Ustilago maydis. Mol. Genet. Genomics 271, 103-110 (2004)

45. Broomfield, P. E. \& Hargreaves, J. A. A single amino-acid change in the iron-sulphur protein subunit of succinate dehydrogenase confers resistance to carboxin in Ustilago maydis. Curr. Genet. 22, 117-121 (1992).

46. Loubradou, G., Brachmann, A., Feldbrugge, M. \& Kahmann, R. A homologue of the transcriptional repressor Ssn6p antagonizes cAMP signalling in Ustilago maydis. Mol. Microbiol. 40, 719-730 (2001).

47. Schuster, M. \& Kahmann, R. CRISPR-Cas9 genome editing approaches in filamentous fungi and oomycetes. Fungal Genet. Biol. 130, 43-53 (2019). 
48. Holliday, R. in Handbook of Genetics Vol. 1 (ed. King, R. C.) Ch. 31 (Plenum Press, 1974).

49. Krombach, S., Reissmann, S., Kreibich, S., Bochen, F. \& Kahmann, R. Virulence function of the Ustilago maydis sterol carrier protein 2. New Phytol. 220, 553-566 (2018)

50. James, P., Halladay, J. \& Craig, E. A. Genomic libraries and a host strain designed for highly efficient two-hybrid selection in yeast. Genetics 144, 1425-1436 (1996).

51. Redkar, A., Jaeger, E. \& Doehlemann, G. Visualization of growth and morphology of fungal hyphae in planta using WGA-AF488 and propidium iodide co-staining. Bio-Protoc. 101, e2942 (2018).

52. Brachmann, A., Weinzierl, G., Kamper, J. \& Kahmann, R. Identification of genes in the bW/bE regulatory cascade in Ustilago maydis. Mol. Microbiol. 42, 1047-1063 (2001)

53. Sesack, S. R., Miner, L. H. \& Omelchenko, N. in Neuroanatomical Tract-Tracing 3 (eds Zaborszky, L. et al.) Ch. 2 (Springer, 2006).

54. Snetselaar, K. M. \& Mims, C. W. Light and electron microscopy of Ustilago maydis hyphae in maize. Mycol. Res. 98, 347-355 (1994).

55. Gómez-Santos, N., Glatter, T., Koebnik, R., Świątek-Połatyńska, M. A. \& Søgaard-Andersen, L. A TonB-dependent transporter is required for secretion of protease PopC across the bacterial outer membrane. Nat. Commun. 10, 1360 (2019).

56. Tyanova, S. et al. The Perseus computational platform for comprehensive analysis of (prote)omics data. Nat. Methods 13, 731-740 (2016).

57. Doehlemann, G., Reissmann, S., Aßmann, D., Fleckenstein, M. \& Kahmann, R. Two linked genes encoding a secreted effector and a membrane protein are essential for Ustilago maydis-induced tumour formation. Mol. Microbiol. 81, 751-766 (2011).

58. Livak, K. J. \& Schmittgen, T. D. Analysis of relative gene expression data using real-time quantitative PCR and the $2^{-\Delta \Delta \mathrm{CT}}$ method. Methods 25, 402-408 (2001).

59. Hoff, K. J. \& Stanke, M. WebAUGUSTUS-a web service for training AUGUSTUS and predicting genes in eukaryotes. Nucleic Acids Res. 41, W123-W128 (2013)

60. Ye, Z. et al. Comparative whole-genome analysis reveals artificial selection effects on Ustilago esculenta genome. DNA Res. 24, 635-648 (2017).

61. Zambanini, T., Buescher, J. M., Meurer, G., Wierckx, N. \& Blank, L. M. Draft genome sequence of Ustilago trichophora RK089, a promising malic acid producer. Genome Announc. 4, e00749-16 (2016).

62. Benevenuto, J., Teixeira-Silva, N. S., Kuramae, E. E., Croll, D. \& Monteiro-Vitorello, C. B. Comparative genomics of smut pathogens: insight from orphans and positively selected genes into host specialization. Front. Microbiol. 9, 660 (2018).

63. Schirawski, J. et al. Pathogenicity determinants in smut fungi revealed by genome comparison. Science 330, 1546-1548 (2010).

64. Schweizer, G. et al. Positively selected effector genes and their contribution to virulence in the smut fungus Sporisorium reilianum. Genome Biol. Evol. 10, 629-645 (2018).

65. Zuther, K. et al. Host specificity of Sporisorium reilianum is tightly linked to generation of the phytoalexin luteolinidin by Sorghum bicolor. Mol. Plant Microbe Interact. 25, 1230-1237 (2012).

66. Dutheil, J. Y. et al. A tale of genome compartmentalization: the evolution of virulence clusters in smut fungi. Genome Biol. Evol. 8, 681-704 (2016).

67. Laurie, J. D. et al. Genome comparison of barley and maize smut fungi reveals targeted loss of RNA silencing components and species-specific presence of transposable elements. Plant Cell 24, 1733-1745 (2012).

68. Rabe, F. et al. A complete toolset for the study of Ustilago bromivora and Brachypodium sp. as a fungal-temperate grass pathosystem. eLife 5, e20522 (2016).

69. Sharma, R., Mishra, B., Runge, F. \& Thines, M. Gene loss rather than gene gain is associated with a host jump from monocots to dicots in the smut fungus Melanopsichium pennsylvanicum. Genome Biol. Evol. 6, 2034-2049 (2014)

70. Madeira, F. et al. The EMBL-EBI search and sequence analysis tools APIs in 2019. Nucleic Acids Res. 47, W636-W641 (2019).

71. Armenteros, J. J. A. et al. SignalP 5.0 improves signal peptide predictions using deep neural networks. Nat. Biotechnol. 37, 420-423 (2019).

72. Krogh, A., Larsson, B., von Heijne, G. \& Sonnhammer, E. L. Predicting transmembrane protein topology with a hidden Markov model: application to complete genomes. J. Mol. Biol. 305, 567-580 (2001).

\section{Acknowledgements}

We acknowledge the many critical discussions with M. Bölker and J. Freitag. We acknowledge the contribution of L. Liang, who did the first co-IP from infected plant material and found Stpl in association with three other fungal effectors and provided the initial characterization of Stp4. We are grateful to S. Kamoun for suggesting the non-host experiment and thank the group of G. Doehlemann (University of Cologne) for providing plasmids for yeast two-hybrid analysis. We thank S. Winterberg, P. Happel K. Münch, L. Liang, L. LoPresti, F. Fukada and Z. Ajami-Rashidi for generating plasmids and strains, M. Muratoglu for help with the stress assay, G. Schweizer, M. Schuster and X. Han for support in bioinformatics analyses, J. Kämper and M. Vraneš for sharing with us unpublished information concerning pst 1 (now stp6) and A. Fagan for helping to develop the immunolabelling technique. We thank A. Zuccaro (University of Cologne) as well as K.-H. Kogel (University of Giessen) for providing barley Golden Promise seeds and are grateful to A. Treuner-Lange for sharing with us the recipe for the detergent-rich buffer prior to publication. Initial studies were supported by the collaborative research centre SFB593 funded by the Deutsche Forschungsgemeinschaft, and the project was generously supported throughout by the Max Planck Society.

\section{Author contributions}

N.L., S.R., C.G., D.A. and M.M. planned and conducted experiments. K. Schipper and L.-S.M. conducted the essential preliminary experiments that the subsequent study was based on. K. Snetselaar conducted the immunoelectron microscopy experiments. K.-H.R. performed the SEM study. T.G. identified proteins by MS. R.K. and S.R. supervised the project. N.L., S.R. and R.K. wrote the manuscript with input from all authors.

\section{Competing interests}

The authors declare no competing interests.

\section{Additional information}

Extended data is available for this paper at https://doi.org/10.1038/s41564-021-00896-x. Supplementary information The online version contains supplementary material available at https://doi.org/10.1038/s41564-021-00896-x.

Correspondence and requests for materials should be addressed to R.K. Reprints and permissions information is available at www.nature.com/reprints. Publisher's note Springer Nature remains neutral with regard to jurisdictional claims in published maps and institutional affiliations.

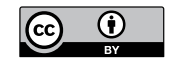

Open Access This article is licensed under a Creative Commons

Attribution 4.0 International License, which permits use, sharing, adaptation, distribution and reproduction in any medium or format, as long as you give appropriate credit to the original author(s) and the source, provide a link to the Creative Commons license, and indicate if changes were made. The images or other third party material in this article are included in the article's Creative Commons license, unless indicated otherwise in a credit line to the material. If material is not included in the article's Creative Commons license and your intended use is not permitted by statutory regulation or exceeds the permitted use, you will need to obtain permission directly from the copyright holder. To view a copy of this license, visit http://creativecommons. org/licenses/by/4.0/.

(c) The Author(s) 2021 


\begin{tabular}{ccc} 
Gene ID & Virulence & Name \\
\hline UMAG_10030 & like wildtype & \\
UMAG_00715 & not virulent & stp3 \\
UMAG_02475 & not virulent & stp1* \\
UMAG_11062 & like wildtype & \\
UMAG_10067 & not virulent & stp2
\end{tabular}

C
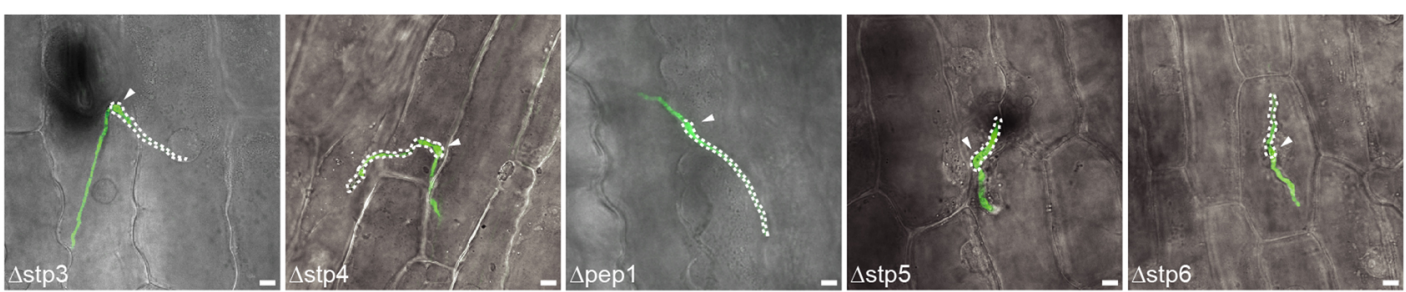

d
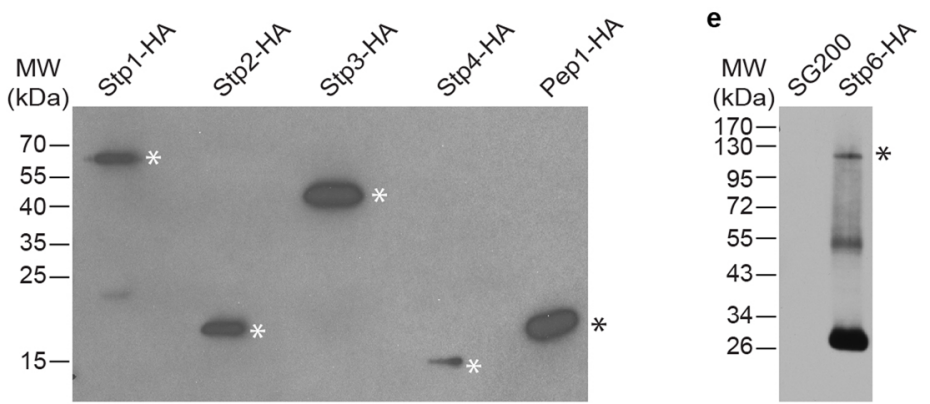

f

h
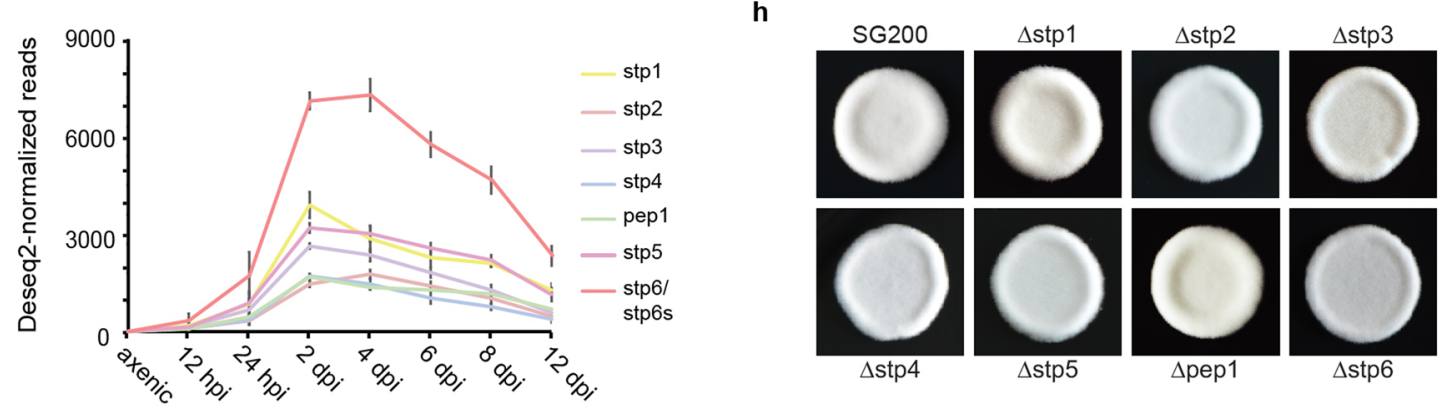

g

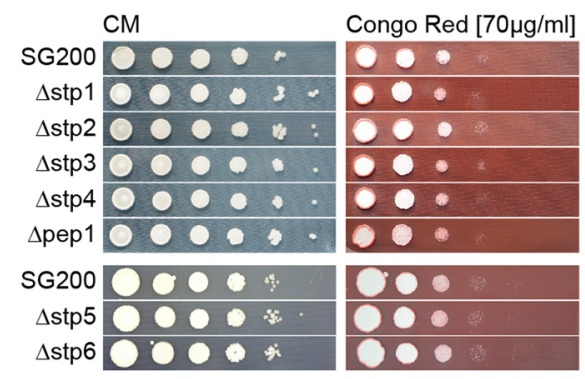

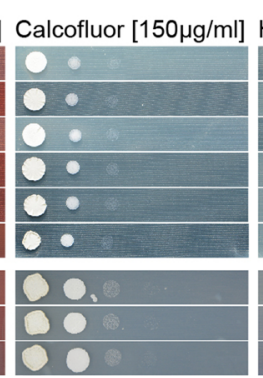

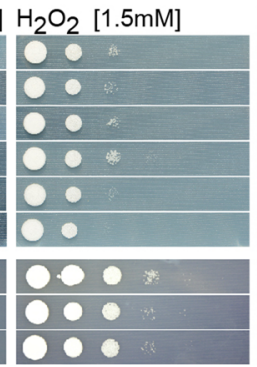

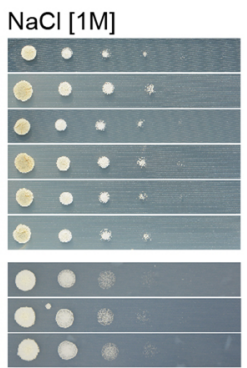

Sorbitol $[2 \mathrm{M}]$ $\square$ No symptoms $\square$ Chlorosis

$\square$ Small tumour

$\square$ Normal tumour

$\square$ Heavy tumour

$\square$ Dead plant

Extended Data Fig. 1 | See next page for caption. 
Extended Data Fig. 1 | Complementation of the stp phenotype with wild type and HA-tagged alleles and characterization of stp deletion strains. a, List of putative effector genes deleted at the onset of this study. The observed virulence phenotype is indicated. * indicates that stp1 was originally deleted as part of the virulence gene cluster $5 b^{18}$ and subsequently shown to be responsible for the loss of virulence ${ }^{19}$. $\mathbf{b}$, Seven-day-old maize seedlings were infected with the indicated $U$. maydis deletion strains, the respective single copy complemented strains (c), as well as deletion strains complemented with the respective single copy HA fusion protein. 12 d.p.i. disease symptoms were scored. The dashed lines separate sets of independent experiments. All data represent mean of $n=3$ biologically independent experiments. Total numbers of infected plants are indicated above the respective columns. $\mathbf{c}$, Maize epidermal cells 1 day post infection with the indicated stp deletion strains in the SG200AN1 or SG200AM1 background. Shown are confocal z-stack maximum projections of GFP (green) and bright-field (grey) channel overlays. Fluorescent hyphae on the plant surface are traced in white, untraced hyphae are intracellular. Arrows indicate appressoria. Scale bars, $5 \mu \mathrm{m}$. d-e, Anti-HA western blot of HA-specific immunoprecipitations from total maize leaf extracts 3 d.p.i. with the indicated U. maydis strains. f, Anti-HA western blot of the total extract ( $T$ ) and eluate after HA-specific immunoprecipitation (IP) obtained from leaves 3 d.p.i. with the strain SG200 $\Delta$ stp5 HA-stp5. The HA-Stp5 protein, indicated by an asterisk, was only detectable after denaturing SDS-PAGE in total extracts (T) but the HA-tag was not accessible to IP under native conditions (IP). The heavy and light chain (hc, Ic) of the HA-antibody used for IP appear here and not in (d) and (e) because in comparison to (d) and (e) the eluate from 10 times more beads was loaded. $\mathbf{g}$, Relative expression levels of stp genes during biotrophic development of $U$. maydis were revealed by RNA sequencing analysis of RNA samples collected from FB1 $\times$ FB2 infected maize plants (dataset available via ref. ${ }^{3}$ and GEO accession number GSE103876). The vertical axis indicates normalized counts from DESeq2 analysis. The horizontal axis indicates the infection stages: 0.5, 1, 2, 4, 6, 8 and 12 d.p.i. Data represent mean \pm s.d. of $n=3$ biological replicates. Colour codes for the different genes are indicated on the right. $\mathbf{h}$, Filamentous growth of the spotted indicated strains was visible on PD-charcoal plates grown for $48 \mathrm{~h}$ at room temperature. $\mathbf{i}$, Stress sensitivity of stp deletion strains. Serial 10 -fold dilutions of SG200 and the indicated deletion strains were spotted on complete medium supplemented with $2 \%(\mathrm{w} / \mathrm{v})$ glucose in the absence of stressors $(\mathrm{CM})$ or in the presence of the indicated stressors. The plates were incubated for $48 \mathrm{~h}$ at $28^{\circ} \mathrm{C}$. 
a

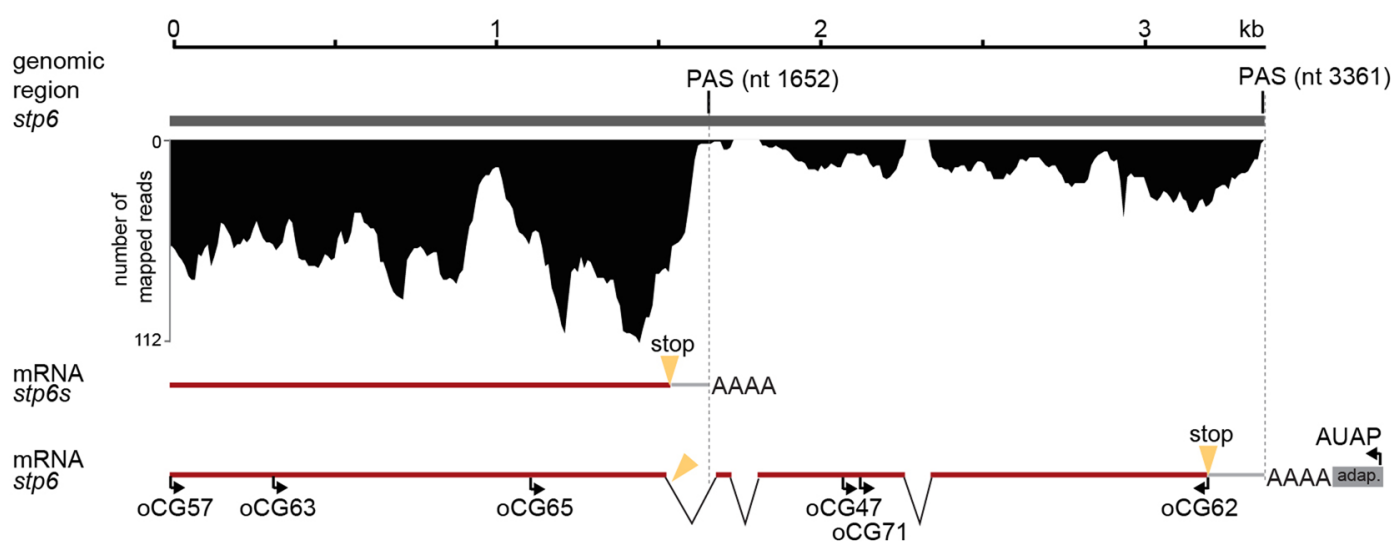

b

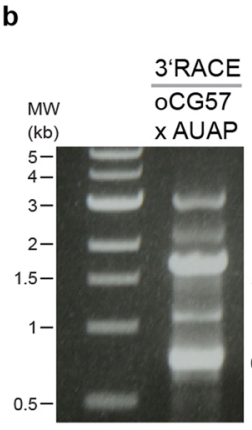

C

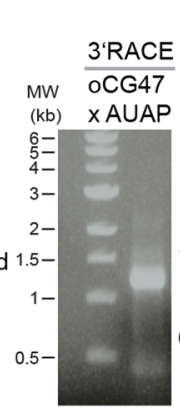

d

stop

MEPE 1677 ACACCGCAAGGTATGATITTGTCCTC

UESC 1599 TCAACGCAAGGTATGATTTCTTCTCT

SPSC 1721 ACACCECAAGGTATEATICTTTCCTC

SPRZ 1497 ACACCGCAAGGTATGATCATCTCCTC

SPRS 1710 ACACCECAAGGTATGATCATC---TC

UTCP 1620 ACACCGCAAGGTATGAT ATCCTTCCT

UTRI 1533 ACECCECAAGGTATEATCTTTCCTCA

UMAG 1521 CCACCECAAGGTATGACITT CCTITT

UBRO 1608 ACACCGTCAGGTATGATCCTACTTTT

UHOR 1620 ACACCATCAGGTATEATCCTACTTTT

UHOO 1678 ACACCATAAGGTATGATCCTACTTTT e

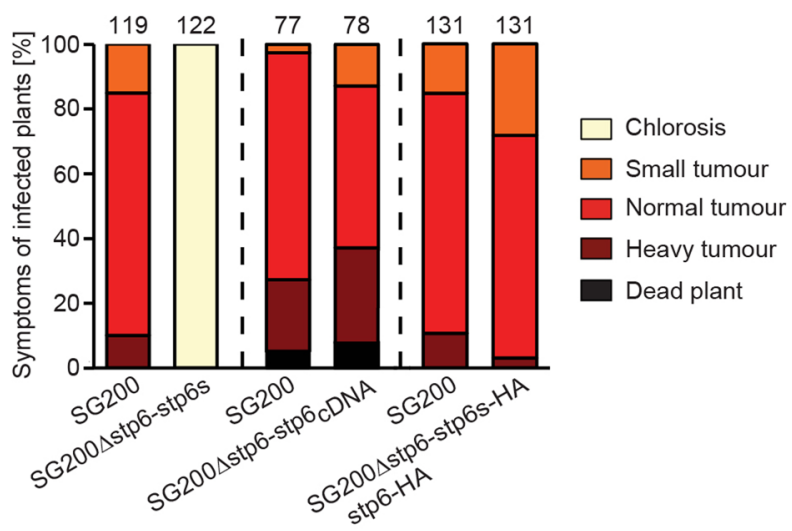

f

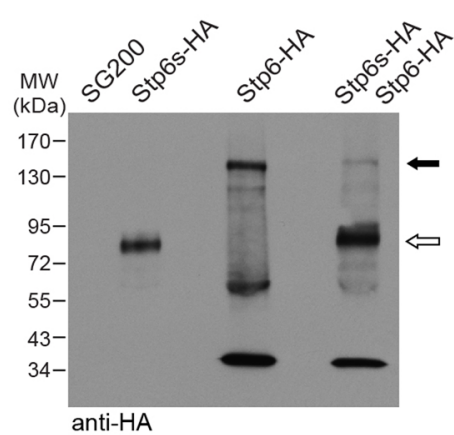

g

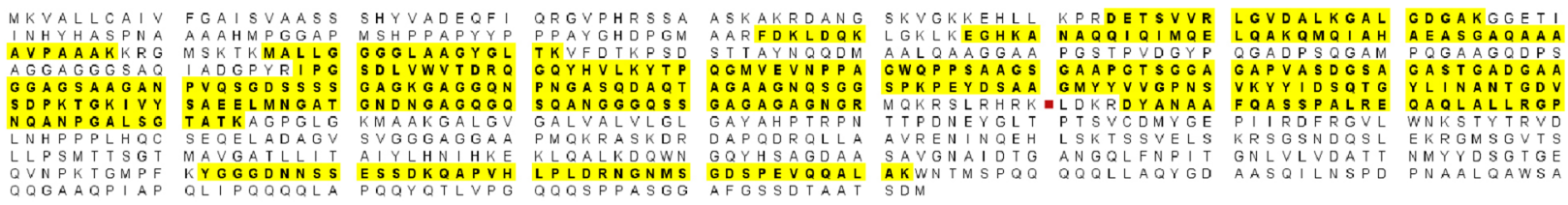

Extended Data Fig. 2 | See next page for caption. 
Extended Data Fig. 2 | Differential polyadenylation of the stp6 mRNA produces in addition to Stp6 a short Stp6s protein lacking the putative transmembrane domain. a, Scheme of the stp6 genomic region. The two polyadenylation sites (PAS) are indicated. Displayed in black are mapped RNA sequencing reads generated from FB1XFB2 infected maize plants 24 hours post infection (dataset available via ref. ${ }^{3}$ and GEO accession number GSE103876). The stp6s and stp6 mRNAs derived from the stp6 genomic region are displayed as red lines. Yellow arrows indicate the stp6s and stp6 stop codons. Note that the stp6s stop codon is located in the first intron of stp6. Binding sites of oligonucleotides used in 3'RACE experiments and nested PCRs are indicated. The differences in abundance result from efficient polyadenylation after nucleotide position 1652 downstream of a stop codon conserved in all orthologues (leading to a 511 amino acid Stp6s (Stp6small) protein that lacks a transmembrane domain. Occasionally the first polyA signal is skipped and polyadenylation occurs after nucleotide 3661. Splicing of this mRNA eliminates the stop codon of stp6s, leading to a 953 amino acid Stp6 protein predicted to have a single transmembrane domain (Supplementary Fig. 7). b-c, DNA gels of products from 3'RACE PCR (left) and the corresponding nested PCR (right) with the indicated primer pairs. AUAP : PolyA adaptor primer provided by the 3'RACE kit. Black arrows indicate PolyA containing fragments of $\operatorname{stp} 6 s(\mathbf{b})$ and $\operatorname{stp} 6(\mathbf{c})$ that were sequenced. $\mathbf{d}$, The stop codon of stp6s is conserved in orthologues genes. Nucleotide sequence alignment of the region containing the stop codon of stp6s from 11 sequenced smut fungi. MEPE: Melanopsichium pennsylvanicum; UESC: Ustilago esculenta; SPSC: Sporisorium scitamineum; SPRZ: Sporisorium reilianum f. sp. zeae; SPRS: Sporisorium reilianum f. sp. sorghi; UTCP: Ustilago trichophora; UTRI: Ustilago tritici; UMAG: U. maydis; UBRO: Ustilago bromivora; UHOR: Ustilago hordei (host: barley); UHOO: Ustilago hordei (host: oats). e, stp6 cDNA complements the stp6 deletion phenotype while stp6s is unable to complement. Seven-day-old maize seedlings were infected with the U. maydis stp6 deletion strain complemented with either stp6s, the stp6 cDNA or the stp6 genomic region with HA-tags inserted directly upstream of the stp6s stop codon and the stp6 stop codon (stp6s-HA stp6-HA). 12 d.p.i. disease symptoms were scored. The dashed lines indicate separate experiments. Data represent mean of $n=3$ biologically independent experiments. Total numbers of infected plants are indicated above the respective columns. f, Detection of Stp6s-HA and Stp6-HA after immunoprecipitation. Plants were infected with strains SG200 $\Delta$ stp6-stp6s-HA (a stp6 deletion strain complemented with the stp6 genomic region with the HA-tag inserted directly upstream of the Stp6s stop codon), SG200 $\Delta$ stp6-stp6-HA (carrying the HA-tag at the C-terminus of Stp6) as well as the SG200 $\Delta$ stp6-stp6s-HA-stp6-HA described in e. Extracts from leaves were generated at 3 d.p.i. and subjected to HA-specific immunoprecipitation. Shown is an anti-HA western blot. Lanes are labeled with the expected HA-tagged proteins expressed. The filled arrow indicates Stp6-HA, the open arrow indicates Stp6s-HA. g, Stp6 is expressed during colonization. Plants were infected with SG200 $\Delta$ stp2-stp2-HA. Extracts from leaves were prepared at 3 d.p.i., subjected to co-IP/MS. Shown is a screenshot from Scaffold (v4.6.2, Proteome Software) of the Stp6 amino acid sequence. Highlighted in yellow are Stp6 peptides identified. The red square marks the end of Stp6s. Peptides identified from the region downstream of Stp6s indicate that the full-length Stp6 protein is expressed and is part of the complex. 
a \begin{tabular}{llllll|} 
& & \\
Pep1 & SP & $\mid$ & $\mid$ & 178aa \\
Pep1 & SP. $\Delta$ & $\mid$ & $\mid$ & 164aa \\
$\Delta 27-42$ & & $\mid$ & $\mid$
\end{tabular}

C

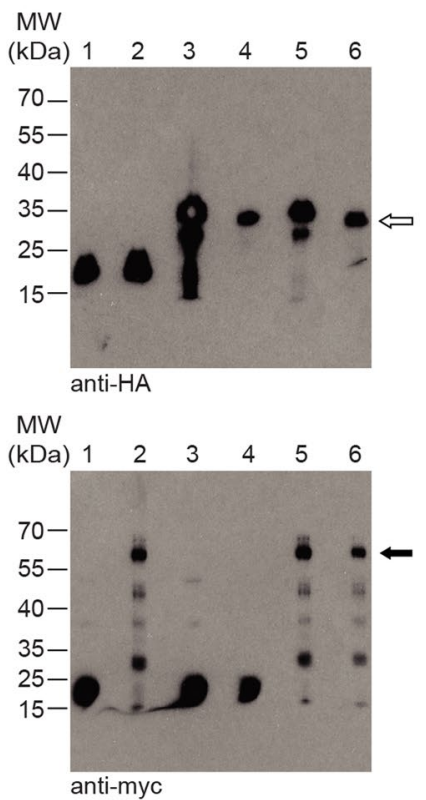

b

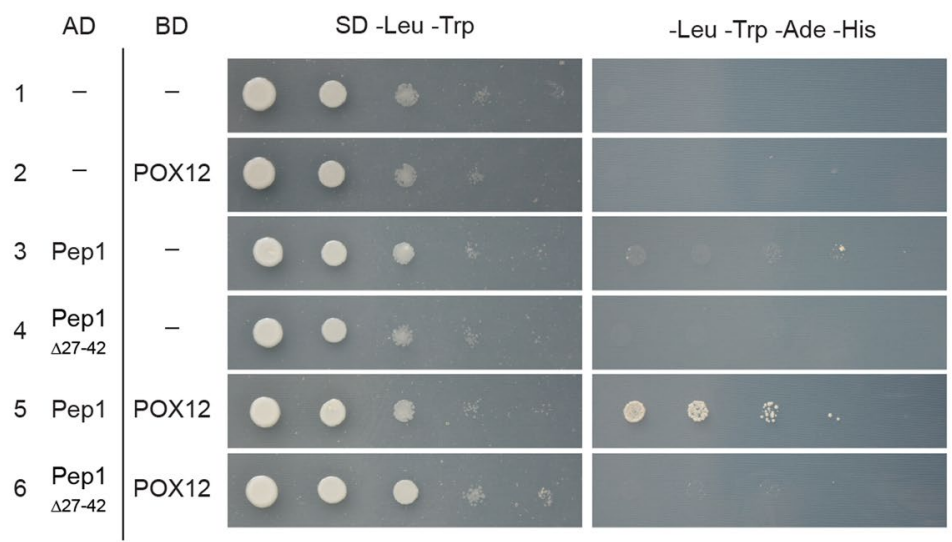

e

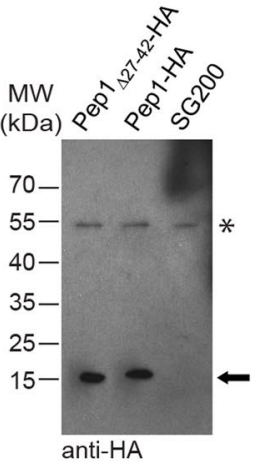

$\square$ No symptoms

Chlorosis

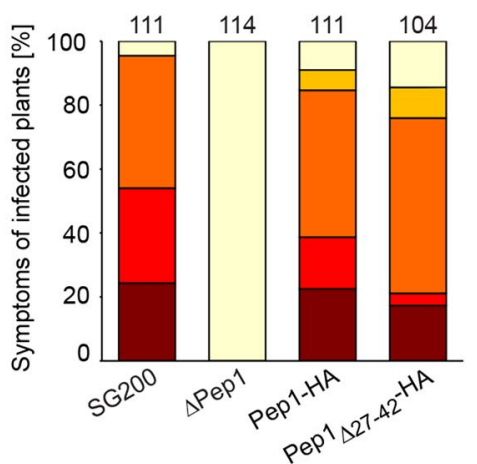

$\square$ Ligular swelling Small tumour
Normal tumour

Heavy tumour

Extended Data Fig. 3 | Pep1 is a dual function effector and its presence in the Stp complex is essential for virulence. a, Scheme of Pep1 and Pep1 $1_{\Delta 27-42 .}$ Violet: signal peptide; black vertical lines: cysteine residues. b, In contrast to the full-length protein, Pep1 ${ }_{\Delta 27-42}$ does not interact with maize POX12. Serial dilutions of $\mathrm{AH} 109$ yeast strains numbered 1 to 6 , co-transformed with two plasmids expressing the indicated proteins without signal peptide as fusion to the GAL4 activation domain (AD) or GAL4 binding domain (BD) were grown on SD -Leu -Trp plates for growth control and SD -Leu -Trp -Ade -His plates to assess protein interaction. $\mathbf{c}$, Expression of the fusion proteins in strains 1-6 from (b) was confirmed by HA-specific western blot for AD fusion proteins (top panel) and Myc-specific western blot for BD fusion proteins (lower panel). The open arrow labels AD-HA-Pep1, the closed arrow labels BD-myc-POX12. d, anti-HA western blot of the eluate after HA-specific immunoprecipitation from total extracts of leaves 3 d.p.i. with $U$. maydis strains expressing the indicated HA-fusion proteins. The arrow marks Pep1. The asterisk marks an unspecific signal. e, Seven-day-old maize seedlings were infected with the indicated U. maydis strains. Disease symptoms were scored at 12 d.p.i. using the disease scores depicted on the bottom. Data represent mean of $n=3$ biologically independent experiments. Total numbers of infected plants are indicated above the respective columns. 
a

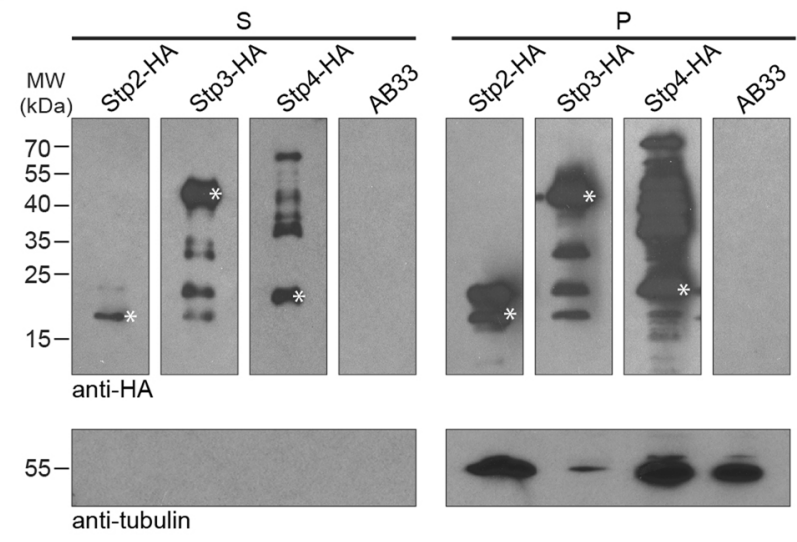

b

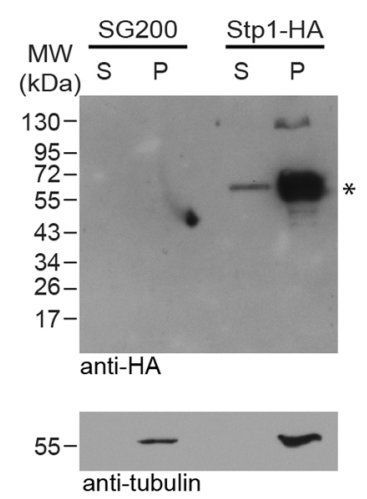

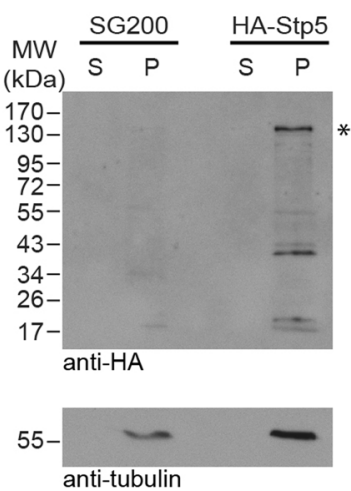

d

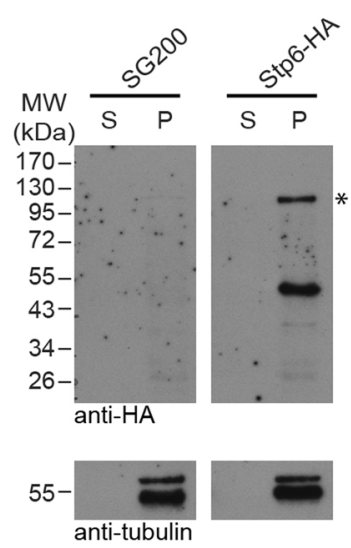

e
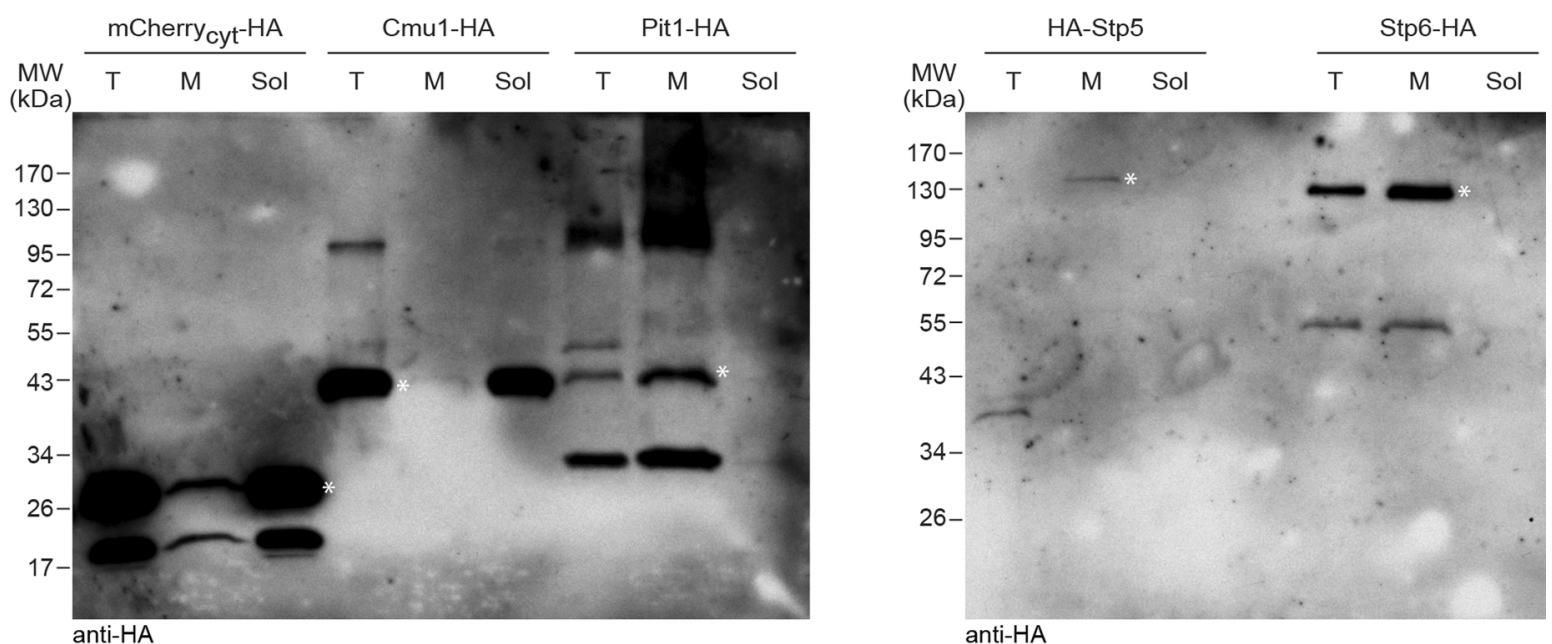

Extended Data Fig. 4 | Stp1, Stp2, Stp3, Stp4 are secreted whereas Stp5 and Stp6 localize to the fungal plasma membrane upon constitutive expression. a-d, HA-specific western blot to reveal secretion of Stp proteins after constitutive expression from the otef promoter in AB33 (a), SG200 $\Delta$ kex2 (b) or SG200 (c, d). Supernatant fractions (S), as well as pellet fractions (P) were loaded. Cultures in (d) were grown in the presence of protease inhibitors. Stp1 contains several predicted Kex2 processing sites (Supplementary Fig. 1) and to detect Stp1-HA in culture supernatants it was necessary to express the protein in a strain lacking kex2. The tubulin specific western blot serves as a lysis control. Proteins of the expected size are marked with an asterisk. The molecular weight in $\mathrm{kDa}$ is indicated. e, HA-specific western blot revealing membrane association of HA-Stp5 and Stp6-HA. Total extract (T), plasma membrane fraction (M) and soluble fraction (Sol) from SG200-derived strains expressing the indicated fusion proteins were loaded. $\mathrm{mCherry}$ cyt serves as control for a cytoplasmic protein, Cmu1-HA serves as control for a secreted protein ${ }^{5}$ and Pit1-HA serves as control for a fungal plasma membrane protein ${ }^{57}$. Full-length proteins are marked with an asterisk and molecular weight markers are indicated. HA-Stp6 co-migrates with an unspecific signal also detected in the pellet fraction of SG200 in (d). 

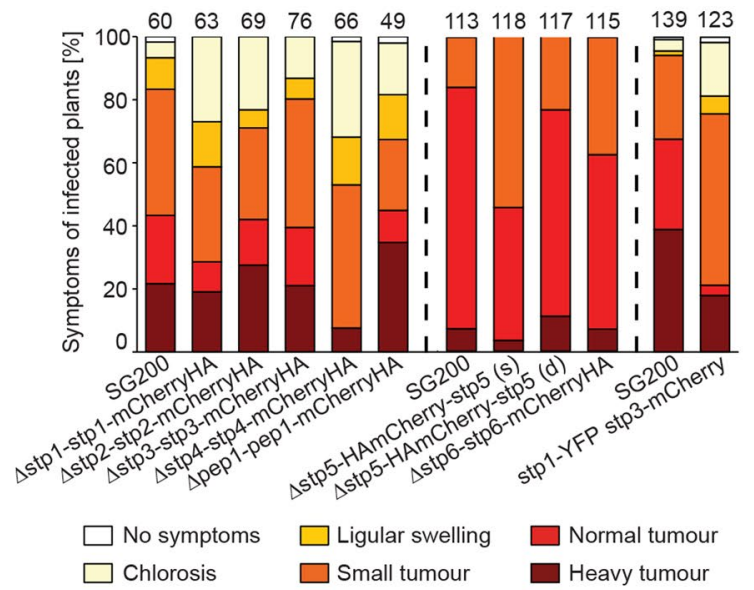

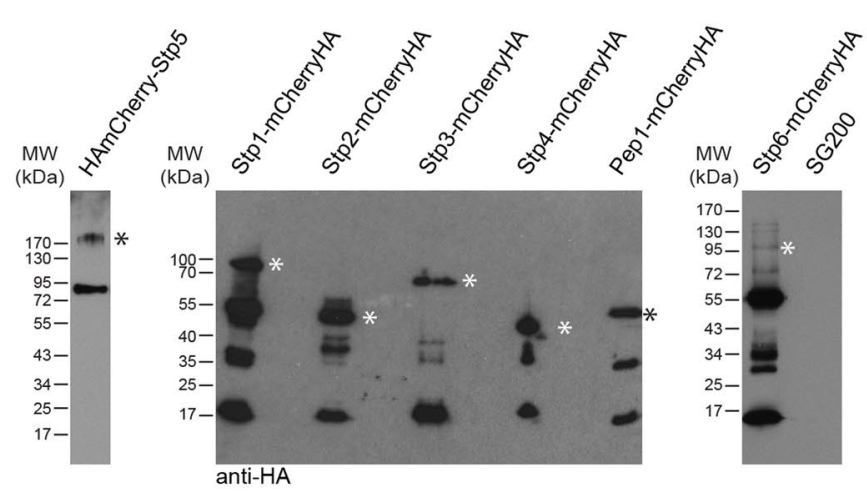

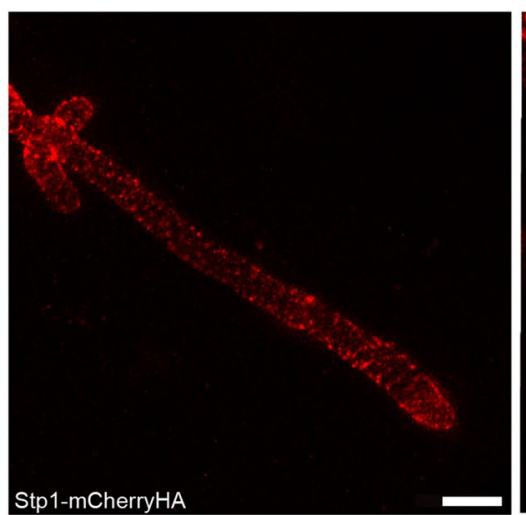
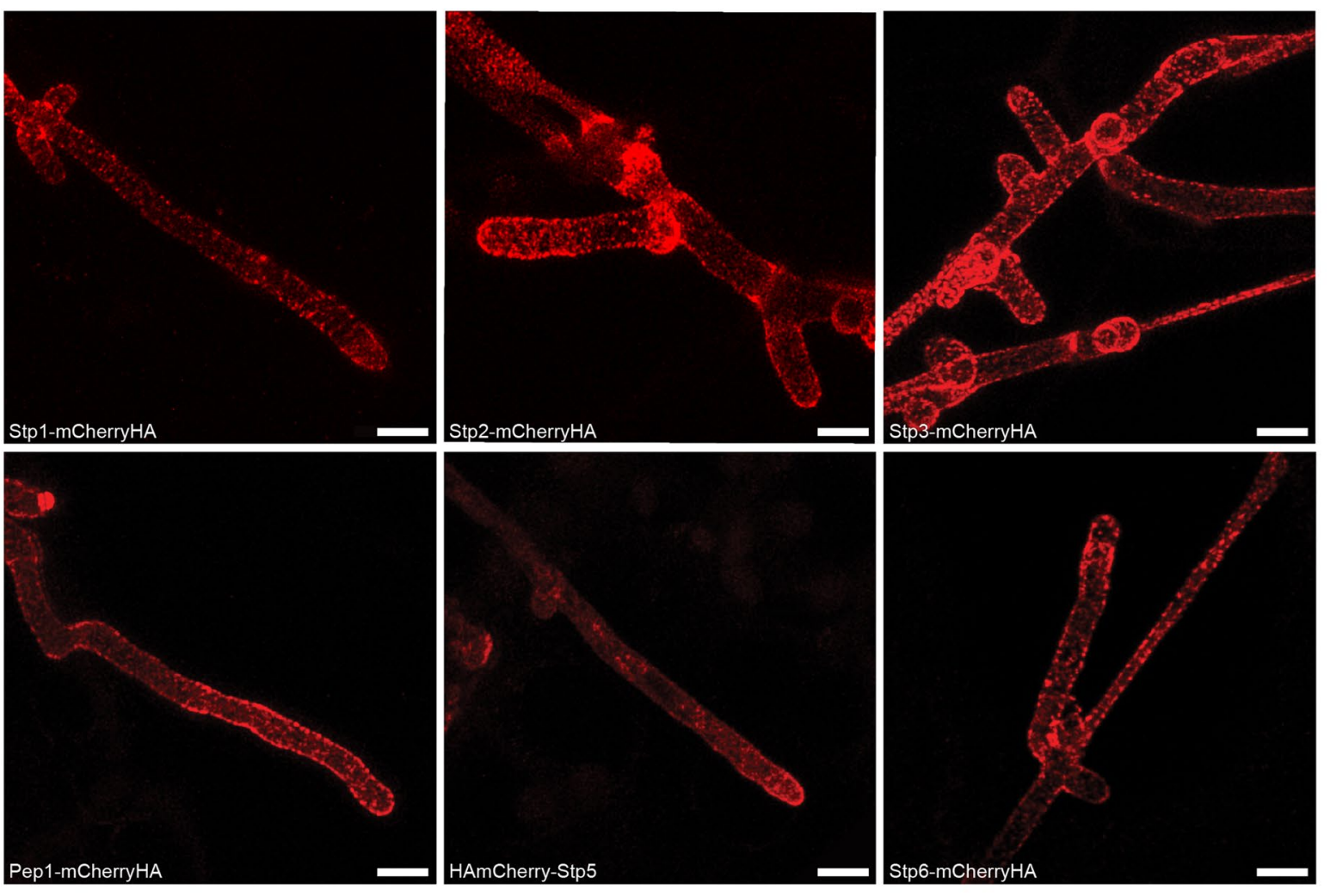

f

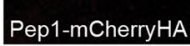

HAmCherry-Stp5
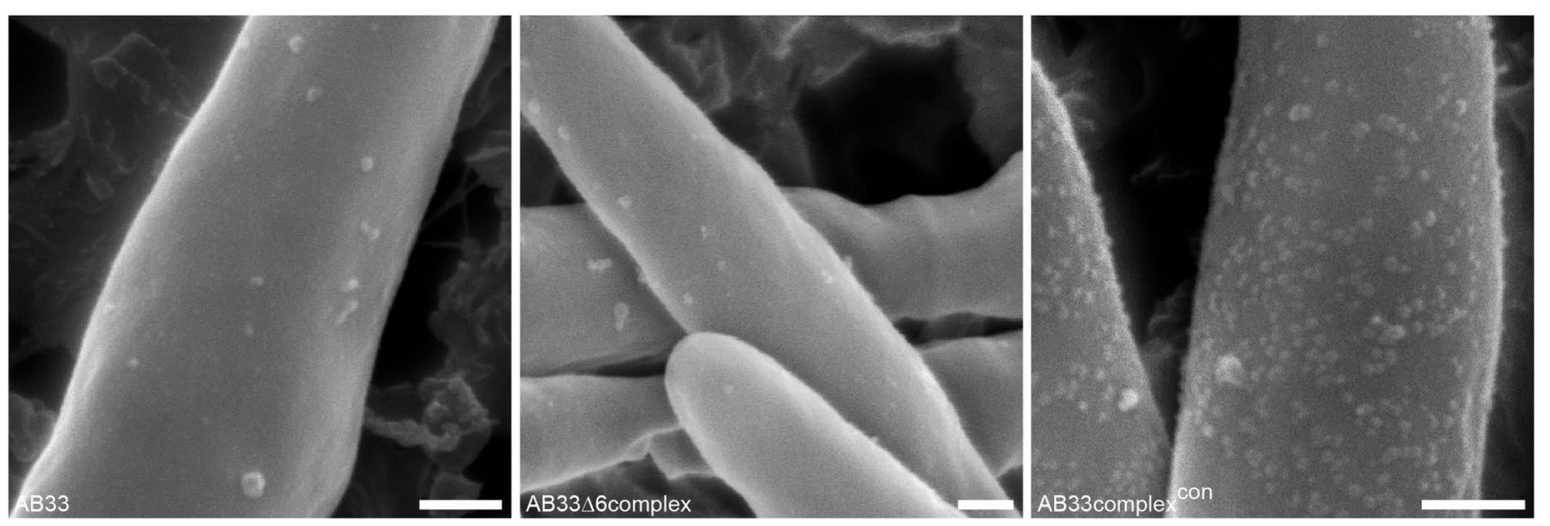

Extended Data Fig. 5 | See next page for caption. 
Extended Data Fig. 5 | Stp-mCherry fusion proteins are functional and localize to speckles surrounding fungal hyphae after plant colonization.

a, Seven-day-old maize seedlings were infected with stp deletion strains complemented with the respective mCherry fusion alleles. For stp5 complementation strains with single (s) as well as two (d) copies of the construct are shown. Dashed lines separate independently tested groups of strains. The rightmost panel presents infections with strain SG200stp1-YFP stp3-mCherry, where both fusion proteins are expressed from genes in their native loci. 12 d.p.i. disease symptoms were scored using the scores depicted below. Data represent mean of $n=3$ biologically independent experiments. Total numbers of infected plants are indicated above the respective columns. $\mathbf{b}$, Anti-HA western blot of the total extract obtained from leaves 3 d.p.i. with strain SG200 $\Delta$ stp5 HAmCherry-stp5 (s). c, d, Anti-HA western blot after HA-specific immunoprecipitations from total maize leaf extracts prepared 3 d.p.i. with the indicated U. maydis strains. b-d, Signals corresponding to full-length fusion proteins are marked with an asterisk. e, Hyphal tips of SG200 strains expressing the indicated $\mathrm{mCherry}$ fusion proteins in the plant epidermis observed 2 d.p.i. mCherry signal: red. The images represent maximum projections of confocal z-stacks. Scale bars, $5 \mu \mathrm{m}$. f, Constitutive expression of all seven complex members changes surface topology of hyphae. Scanning electron micrographs (SEM) of $A B 33$ and $A B 33 \Delta 6$ complex show smooth hyphae with single scattered structures on the surface. In $A B 33 c o m p l e x{ }^{\text {con }}$ a large number of small surface exposed structures are seen in addition. Scale bars, $500 \mathrm{~nm}$. 
a

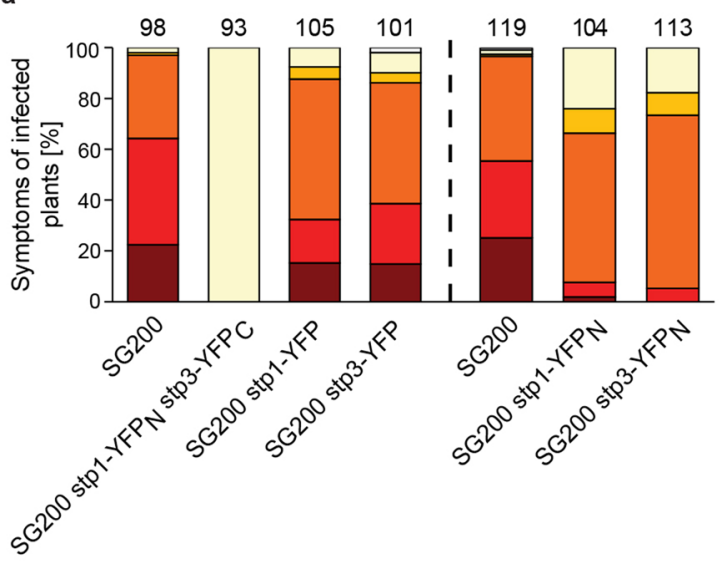

b

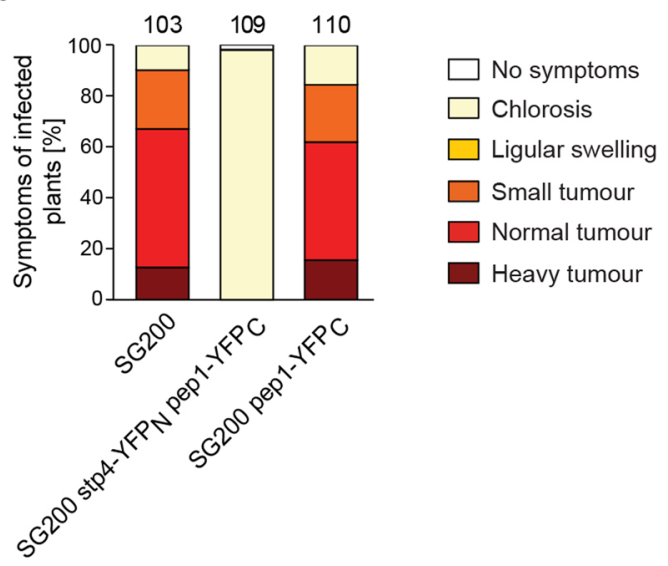

Extended Data Fig. 6 | Virulence assays of strains expressing C- or N-terminal halves of YFP. Seven-day-old maize seedlings were infected with the indicated strains. 12 d.p.i. disease symptoms were scored using the colour code depicted on the right. The dashed lines indicate separate experiments. All data represent mean of $n=3$ biologically independent experiments. Total numbers of infected plants are indicated above the respective columns. Infections with the control strain SG200 on the left were done in parallel with the infections shown in Fig. 3 on the left and are therefore displayed in both figures. 


\section{ARTICLES}

a
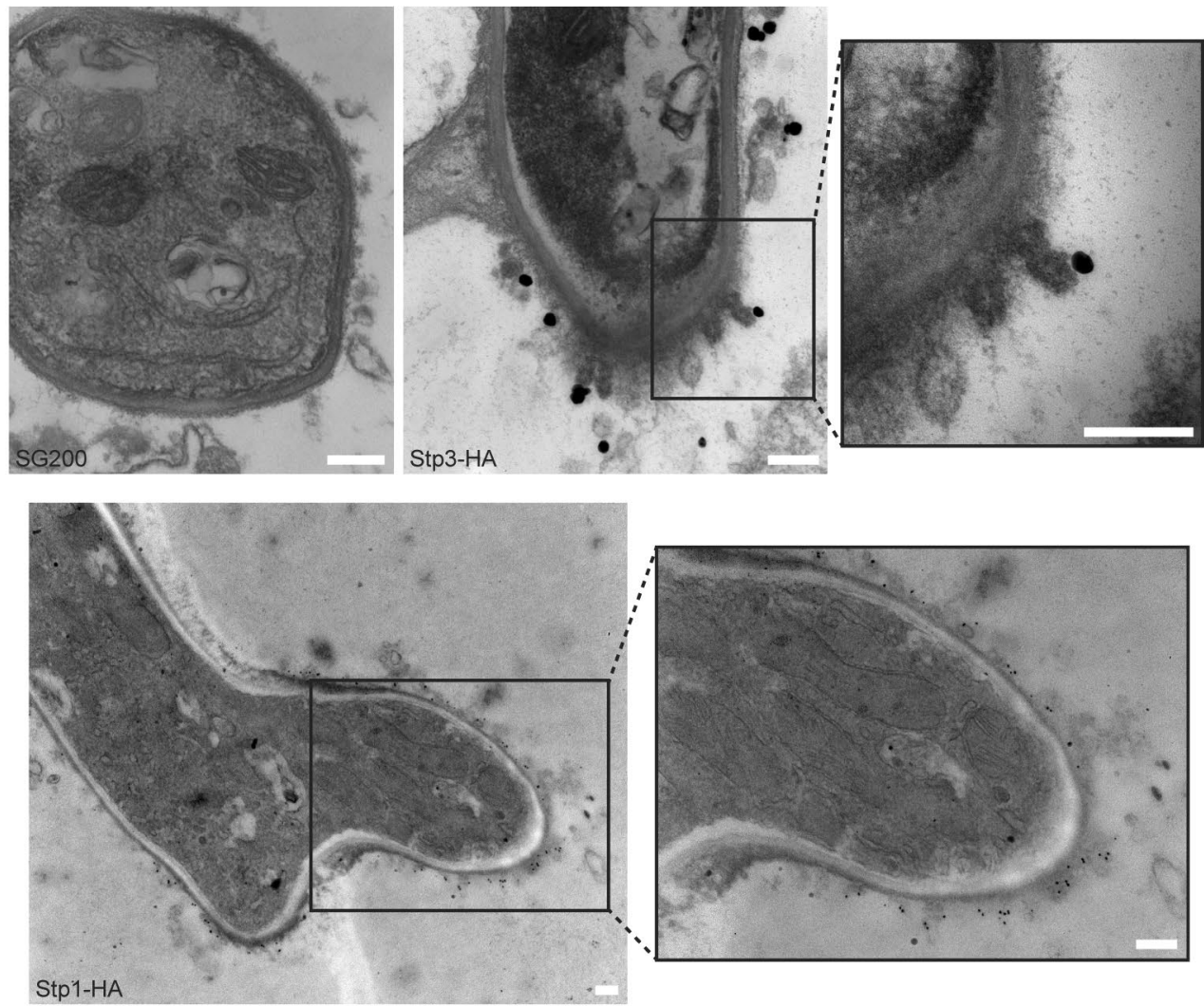

b
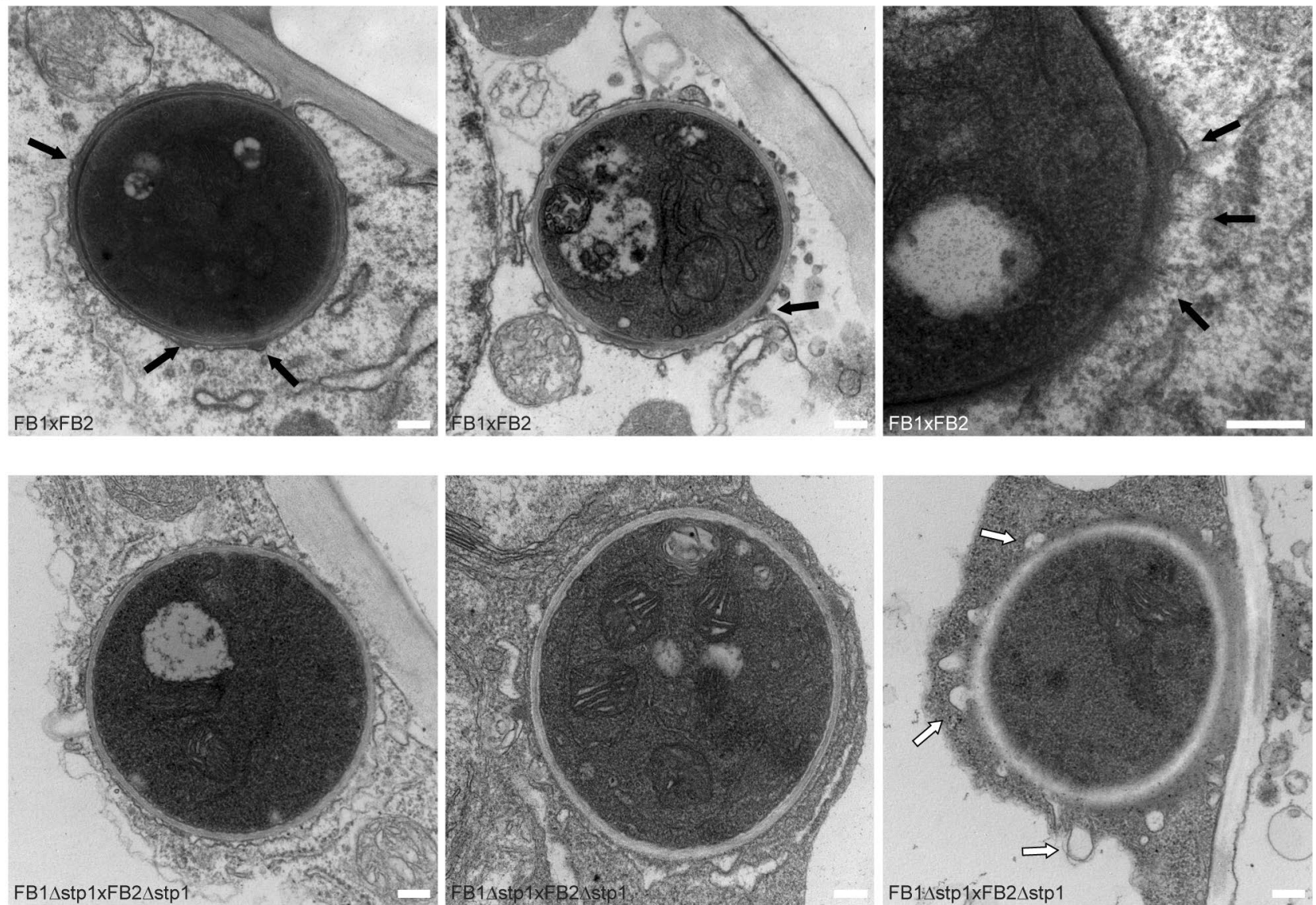

Extended Data Fig. 7 | See next page for caption. 
Extended Data Fig. 7 | The plant-fungus interaction zone visualized by EM. a, Silver-enhanced immunogold labeling of Stp1-HA and Stp3-HA in biotrophic hyphae. Immuno-labeled hyphal tips inside epidermal plant cells are viewed with transmission electron microscopy. Images confirm specificity of the antibody (no signal in SG200 hyphae) and presence of signals in SG200 $\Delta$ stp1 Stp1-HA and SG200 $\Delta$ stp3 Stp3-HA. Particle size varies with silver enhancement time. b, Cross sections of active fungal hyphae in plant cells visualized by EM. Strains are indicated on the left. Filled arrows indicate electron-dense structures. Open arrows indicate empty vesicular structures. Note that the interaction zone in wild-type infections includes electron-dense structures that are approximately $50 \mathrm{~nm}$. Scale bars, $200 \mathrm{~nm}$. 


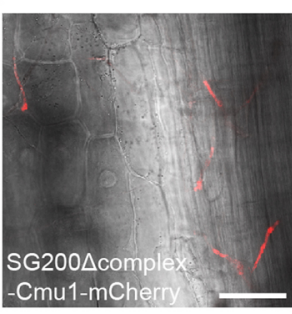

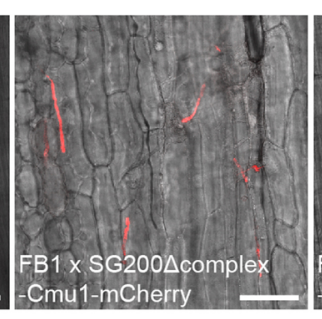

b

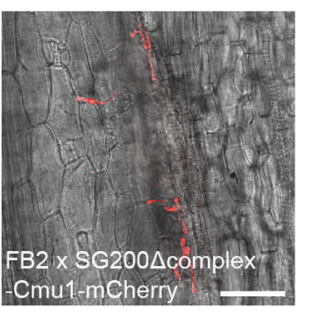

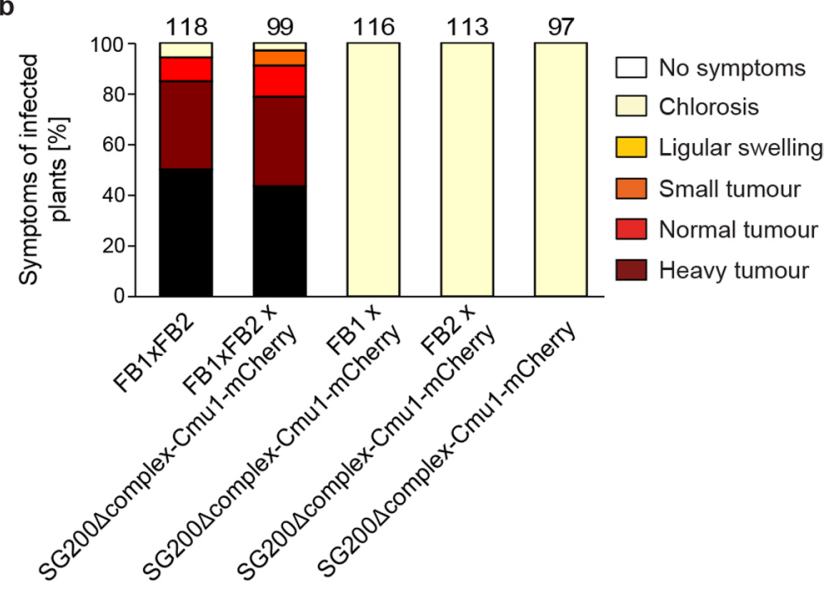

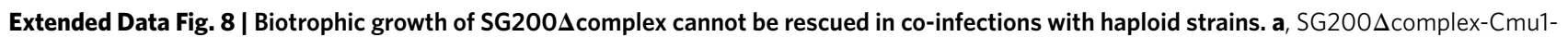
mCherry (red) was infected alone or co-infected with either FB1 or FB2 and analysed by confocal microscopy as indicated. Growth of SG200 $\Delta$ complexCmu1mCherry could not be rescued by co-infections with FB1 or FB2. This illustrates that these haploid cells are unable to fuse with SG200 $\Delta$ complexCmu1-mCherry. Shown are maximum projections of confocal z-stacks. Scale bars, $50 \mu \mathrm{m}$. b. Maize seedlings were infected with the indicated strains. 12 d.p.i. disease symptoms were scored using the colour code shown on the right. Data represent mean of $n=3$ biologically independent experiments. Total numbers of infected plants are indicated above the respective columns. 


\section{Reporting Summary}

Nature Research wishes to improve the reproducibility of the work that we publish. This form provides structure for consistency and transparency in reporting. For further information on Nature Research policies, see our Editorial Policies and the Editorial Policy Checklist.

\section{Statistics}

For all statistical analyses, confirm that the following items are present in the figure legend, table legend, main text, or Methods section.

n/a Confirmed

$\square$ The exact sample size $(n)$ for each experimental group/condition, given as a discrete number and unit of measurement

$\square$ \ A statement on whether measurements were taken from distinct samples or whether the same sample was measured repeatedly

$\square$ The statistical test(s) used AND whether they are one- or two-sided

$\square$ Only common tests should be described solely by name; describe more complex techniques in the Methods section.

Х $\square$ A description of all covariates tested

Х $\square$ A description of any assumptions or corrections, such as tests of normality and adjustment for multiple comparisons

$\searrow$ A full description of the statistical parameters including central tendency (e.g. means) or other basic estimates (e.g. regression coefficient)

$\bigotimes$ AND variation (e.g. standard deviation) or associated estimates of uncertainty (e.g. confidence intervals)

$\varnothing$ For null hypothesis testing, the test statistic (e.g. $F, t, r$ ) with confidence intervals, effect sizes, degrees of freedom and $P$ value noted

\ive $P$ values as exact values whenever suitable.

\ $\square$ For Bayesian analysis, information on the choice of priors and Markov chain Monte Carlo settings

$\bigotimes \square$ For hierarchical and complex designs, identification of the appropriate level for tests and full reporting of outcomes

Х $\square$ Estimates of effect sizes (e.g. Cohen's $d$, Pearson's $r$ ), indicating how they were calculated

Our web collection on statistics for biologists contains articles on many of the points above.

\section{Software and code}

Policy information about availability of computer code

Data collection GPCR data was collected by CFX manager software (Biorad). Confocal microscopy was performed using a Leica TCS SP8x/WLL (White Light Laser) confocal laser-scanning microscope (Leica, Wetzlar, Germany). For image deconvolution the HyVolution software package (Leica and Scientific Volume Imaging B.V., Hilversum, Netherlands) was used.

Data analysis Exel 2013 (Microsoft), Mascot 2.5 (Matrix Science), Scaffold (v4.6.2, Proteome Software), Cytoscape (v3.3.0), MaxQuant (Version 1.6.3.4), Perseus (v1.5.2.6), CLC genomics workbench (Qiagen, version 9.5.3), Augustus gene prediction program (Version 2019 (http://bioinf.unigreifswald.de/augustus/)), Clustal Omega provided by the Swiss Institute of Bioinformatics (Version 2019 (https://www.ebi.ac.uk/Tools/msa/ clustalo/)), BOXSHADE (Version 3.21 provided by the EMBnet (https://embnet.vitalit.ch/software/BOX_form.html)), SignalP v. 5 (http:// www.cbs.dtu.dk/services/SignalP/), TMHMM v. 2.0. (http://www.cbs.dtu.dk/services/TMHMM/), GraphPad Software, Inc. Prism 8.1 (https:// www.graphpad.com), Leica Application Suite X, version 3.1.5.

For manuscripts utilizing custom algorithms or software that are central to the research but not yet described in published literature, software must be made available to editors and reviewers. We strongly encourage code deposition in a community repository (e.g. GitHub). See the Nature Research guidelines for submitting code \& software for further information.

\section{Data}

Policy information about availability of data

All manuscripts must include a data availability statement. This statement should provide the following information, where applicable:

- Accession codes, unique identifiers, or web links for publicly available datasets

- A list of figures that have associated raw data

- A description of any restrictions on data availability

U. maydis genes and encoding protein sequences are available at NCBI under the following accession numbers: U. maydis stp1 (UMAG_02475), XP_011388756.1; U. 
maydis stp2 (UMAG_10067), XP_011388794.1; U. maydis stp3 (UMAG_00715), XP_011386505.1; U. maydis stp4 (UMAG_12197), XP_011389576.1; U. maydis pep1 (UMAG_01987), XP_011387901.1; U. maydis stp5 (UMAG_04342), XP_011391052.1; U. maydis stp6 (UMAG_01695), XP_011387671.1

Protein and DNA sequences of stp orthologues from 11 sequenced smuts were derived from the following data sources: U. esculenta: DDBJ/EMBL/GenBank accession number JTLW00000000, version JTLW0100000059, U. trichophora RK089: DDBJ/ENA/GenBank accession number LVYE00000000, version LVYE0100000060, U. tritici: DDBJ/ENA/GenBank accession number NSHH0000000, version NSHH0100000061, Sporisorium reilianum f.sp. zeae SRZ2: European Molecular Biology Laboratory database accession numbers FQ311430 to FQ31147462, Sporisorium reilianum f.sp. reilianum SRS1 H2-8: European Nucleotide Archive (ENA) at http://www.ebi.ac.uk/ena/data/view/LT795054-LT79507663,64, Sporisorium scitamineum Sscl8: ENA at http://www.ebi.ac.uk/ena/data/view/ LK056649-LK05669565. U. maydis 521: https://mycocosm.jgi.doe.gov/Ustma2_2/Ustma2_2.home.html18, U. hordei Uhor01: DDBJ/ENA/GenBank accession number NSDP00000000 version NSDP0100000061, U. hordei Uh4875-4: ENA at http://www.ebi.ac.uk/ena/data/view/ accession numbers CAGI01000001 to CAGI0100071366, U. bromivora UB2112: ENA at http://www.ebi.ac.uk/ena/data/view/PRJEB7751 accession number PRJEB775167, M. pennsylvanicum Mp4: ENA at accession number PRJEB4565, accession IDs HG529494 to HG52992868. M. pennsylvanicum Mp4 was resequenced by PacBio and gene information from this project was included (R. K., unpublished).

The data that support the findings of this study are available from the corresponding author upon request.

\section{Field-specific reporting}

Please select the one below that is the best fit for your research. If you are not sure, read the appropriate sections before making your selection. $\bigotimes$ Life sciences $\quad \square$ Behavioural \& social sciences $\square$ Ecological, evolutionary \& environmental sciences

For a reference copy of the document with all sections, see nature.com/documents/nr-reporting-summary-flat.pdf

\section{Life sciences study design}

All studies must disclose on these points even when the disclosure is negative.

Sample size

Plant infections with Ustilago maydis strains to be tested were done in 3 biological replicates with about 30 to 40 plants for each replicate. Individual plants were scored for disease severity using a published scoring scheme. Only infections done at the same time are grouped together.

Data exclusions No data were excluded from the analysis.

Replication In cases where representative pictures are shown the experiments were repeated at least twice with similar results

Randomization No randomization was necessary.

Blinding Blinding was not relevant for our study.

\section{Reporting for specific materials, systems and methods}

We require information from authors about some types of materials, experimental systems and methods used in many studies. Here, indicate whether each material, system or method listed is relevant to your study. If you are not sure if a list item applies to your research, read the appropriate section before selecting a response.

Materials \& experimental systems

\begin{tabular}{l|l}
\hline$n / a$ & Involved in the study \\
\hline & $\square$ Antibodies \\
$\square$ & $\square$ Eukaryotic cell lines \\
$\square$ & $\square$ Clinical data \\
$\square$ Dumal & $\square$ Dual use research of concern
\end{tabular}

\begin{tabular}{l|l}
\multicolumn{2}{l}{ Methods } \\
\hline n/a & Involved in the study \\
$\square$ & $\square$ ChIP-seq \\
$\square$ & $\square$ Flow cytometry \\
$\bigotimes$ & $\square$ MRI-based neuroimaging
\end{tabular}

Antibodies

Antibodies used

Rabbit anti-HA primary antibody from rabbit for HA-protein fusion detection (1:10.000 dilution, Sigma-Aldrich, H6908, polyclonal, Lot\#015M4868V),

Mouse anti-HA monoclonal primary antibody from mouse for HA-protein fusion detection (1:5.000 dilution, Sigma-Aldrich, H9658, clone HA-7, Lot\#127M4869V)

Mouse anti-myc monoclonal primary antibody from mouse for myc-protein fusion detection (1:10.000 dilution, Sigma-Aldrich, M4439, Clone9E10, Lot\#087M4765V) 
Anti-a-tubulin monoclonal primary antibody from mouse (1:2.000 dilution, Calbiochem ${ }^{\circledR}$, CP06, Clone DM1A, Lot\#2681308)

Anti-rabbit lgG secondary antibody (1:10.000 dilution, Cell Signaling Technology \#7074)

Anti-mouse IgG secondary antibody (1:10.000 dilution Cell Signaling Technology \#7076)

For Immunolocalization:

Mouse anti-HA monoclonal primary antibody from mouse for HA-protein fusion detection (1 : 1500 dilution, Sigma-Aldrich, H9658, clone HA-7, Lot\#089M4796V)

Alexa Fluor 488 goat anti-mouse lgG (H+L) (1 : 1500 dilution, Life Technologies Lot\#1890503)

For Immuno-TEM:

Primary: 1:60 dilution, Thermofisher Catalog \#26183 Invitrogen HA Tag Monoclonal Antibody (2-2.2.14),

Secondary: 1:50 dilution, Electron Microscopy Sciences \#25121 Aurion Goat anti-mouse IgG Ultra Small Lot\# GG-71025/2

Validation

All antibodies directed against epitope-tags were validated by using them on strains not expressing the epitope -tagged protein either by immuno-EM or by western. Respective controls are included and where antibodies recognize non-epitope-tagged proteins on western blots these are indicated.

All commercial antibodies are validated by the manufacturer and the statements are available on the manufacturer's website. 